\title{
Nasotemporal Overlap of Crossed and Uncrossed Retinal Ganglion Cell Projections in the Japanese Monkey (Macaca fuscata)
}

\author{
Yutaka Fukuda, ${ }^{1}$ Hajime Sawai, ${ }^{1}$ Masami Watanabe, ${ }^{2, a}$ Kazuo Wakakuwa $^{1, b}$ and Katsuko Morigiwa ${ }^{1}$ \\ ${ }^{1}$ Department of Neurophysiology, and 'Department of Anatomy, Osaka University Medical School, Kita-ku, Osaka, \\ Japan 530
}

\begin{abstract}
The nasotemporal overlap of crossed and uncrossed retinal ganglion cell projections were studied in 11 Japanese monkeys (Macaca fuscata) using HRP and fluorescent dyes (DAPI and $\mathrm{RITC}$ ) as retrograde tracers and by physiological recordings of antidromic field potentials. A strip of nasotemporal overlap ran orthogonal to the horizontal meridian in all the whole-mount retinas studied. In HRP-labeled retinas of 6 monkeys, the width of the overlap gradually increased from $0.6^{\circ}$ in the central retina up to $5^{\circ}$ at eccentricity of $5 \mathrm{~mm}$, and to $15^{\circ}$ at the extreme periphery. We also noted a clear asymmetric distribution of crossed and uncrossed retinal ganglion cell projections particularly in the perifoveal region; ipsilaterally projecting cells encircled the nasal edge of the fovea, whereas few contralaterally projecting cells were observed in the temporal edge. Soma-size analysis revealed that crossed projections in the temporal portion of the overlap arose mainly from large and small cells (presumably $P \alpha$ and $\mathrm{P}_{\gamma}$ cells, respectively); uncrossed projections in its nasal portion arose from medium-sized cells (presumably $P \beta$ cell). Direct evidence of the overlap as well as of the asymmetry was obtained in subsequent fluorescent dye experiments in 3 monkeys. Physiological studies on 2 additional monkeys confirmed the widening of the nasotemporal overlap towards the upper and lower parts of the retina. Moreover, in the nasal portion of the overlap, only slow potentials, which presumably reflect activities of $P \beta$ cells, were recorded after stimulation of the ipsilateral LGN as expected from the morphological study. The findings are discussed in relation to clinical observations of macular sparing and splitting, and
\end{abstract}

\footnotetext{
Received July 7, 1988; revised Nov, 4, 1988; accepted Nov. 7, 1988.

We thank the Section of Industry and Economy, Kanaya Municipal Office (Arita, Wakayama) and the Department of Comparative Developmental Psychology, Faculty of Human Sciences, Osaka University for kindly providing Japanese monkeys; Narishige Scientific Instrument Laboratory (Tokyo) for the spccial stereotaxic apparatus for intraretinal recordings; and San Contact Lens Company (Kyoto) for contact lenses for each monkey. We are also grateful to the members of Behavioral Physiology, Tokyo Metropolitan Institute for Neurosciences and those of Electrotechnical Laboratory (Osaka) for instructing us in the basic procedures of acute experiments on monkeys; to Dr. T. Arikuni for his enduring support and encouragement; and to Dr. M. Tauchi for kindly introducing us to the use of fluorescent dyes as a retrograde tracer. This work was supported by a Grant-in-Aid for Scientific Researches (58480113 and 61570066) from the Ministry of Education, Science and Culture of Japan, and the ATR (Advanced Telecommunications Research Institute).

Correspondence should be addressed to Y. Fukuda at the above address.

a Present address: Department of Physiology, Institute for Developmental Research, Aichi Prefectural Colony, Kasugai, Aichi, 480-03, Japan.

b Present address: Departamento de Fisiologia, Centro de Ciências Biólogicas, Universidade Federal do Para, Belém-Pará, Brazil.

Copyright (C) 1989 Society for Neuroscience $0270-6474 / 89 / 072353-21 \$ 02.00 / 0$
}

with regard to the functional differences between $P \alpha$ and $P \beta$ cell systems on which binocular stereoscopic vision along the midsagittal plane may be based.

In most mammals with frontalized eyes, ganglion cells in the temporal retina project to the ipsilateral optic tract and those in nasal retina project to the contralateral optic tract. However, binocular stereopsis along the midsagittal plane would not be possible if crossed and uncrossed projections were to be exactly split along the vertical meridian passing through the fovea (Blakemore, 1969; Bishop, 1981). The objects located nearer or farther from the fixation point along that plane would then be projected to only one hemisphere through the 2 eyes. In fact, previous anatomical and physiological studies on the monkey as well as on the cat retina provided evidence of a strip of overlap where ipsilaterally and contralaterally projecting ganglion cells intermingle.

Stone et al. (1973) first showed in Nissl-stained whole-mount retinas of the rhesus monkey that there is a nasotemporal overlap about $1^{\circ}$ in width in the central retina. After unilateral section of the optic tract, the distribution of surviving ganglion cells was not merely confined to the unaffected hemiretina but was slightly extended into the other hemiretina where most of the ganglion cells were degenerated. However, unequivocal identification of ganglion cells from the neuroglia was difficult based solely on their Nissl-stained materials. Subsequently, Bunt and her associates (Bunt and Minckler, 1977; Bunt et al., 1977) retrogradely labeled ganglion cells by injecting HRP into the LGN of the macaque monkey (Macaca fascicularis). They confirmed that the nasotemporal overlap was $1^{\circ}$ wide in central retina and reported that the overlap became wider, up to $3^{\circ}$, around the foveola suggesting that this pattern could represent an anatomical basis for foveal sparing, although it would not be consistent with foveal splitting.

Both of these studies are limited in the way they have examined the nasotemporal overlap, and our understanding of its functional significance is still rudimentary. To elucidate the functional role of the overlap, namely in primate binocular stereopsis of the midsagittal plane, we combined morphological methods, using HRP and fluorescent dyes as retrograde tracers, with physiological experiments. First, for a more elaborate picture of the overlap, we investigated the overlap width in the upper and lower peripheries and the detailed distributions of crossed and uncrossed retinal ganglion cell projections. We injected a large amount of HRP into the left (or right) optic tract of 6 monkeys and quantitatively analyzed the distributions of contra- and ipsilaterally projecting ganglion cells in whole-mount 
retinas. The results showed that the nasotemporal overlap is considerably wider in the upper and lower periphery, up to $15^{\circ}$, while in central retina it is less than $1^{\circ}$ in horizontal width. Importantly, crossed and uncrossed projections are not evenly distributed along the vertical meridian of the overlap. Particularly in the perifoveal region, the uncrossed projections arise from the foveal region of the nasal retina, whereas the crossed projections do not arise from the foveal region of the temporal retina. This asymmetry may partly account for the discrepant clinical observations, i.e., "macular sparing" and "macular splitting" (Spalding, 1952; Huber, 1970; Kocrncr and Tcuber, 1973; Harrington, 1981).

To obtain further evidence, we labeled ganglion cells in 3 monkeys with 2 kinds of fluorescent dyes excited by different wavelengths. We injected 4', 6-Diamidino-2-phenylindol-2 $\mathrm{HCl}$ [DAPI (Kuypers et al., 1977; Sarthy and Belkema, 1981)] into the left (or right) LGN and rhodamine-B-isothiocyanate [RITC (Thanos et al., 1987)] into the other LGN, and observed bilateral whole-mount retinas under an epifluorescence microscope. The results confirm both the widening of the overlap towards the peripheral retina and the asymmetric distributions of crossed and uncrossed projections along the vertical meridian in peripheral and perifoveal regions.

Second, in HRP-labeled whole-mount retinas we examined the cell composite of crossed and uncrossed projections in the overlap. Morphological types of ganglion cells in the primate retina have recently been identified as $\alpha \mathrm{M}, \beta \mathrm{M}$, and $\gamma \mathrm{M}$ cells (Suyama, 1986) in the Japanese monkey or as $\mathrm{P} \alpha, \mathrm{P} \beta, \mathrm{P} \gamma$, and P $\epsilon$ cells (Perry and Cowey, 1984; Perry et al., 1984) or A, B, C, and E cells (Leventhal et al., 1981) or as parasol and midget cells (Rodieck et al., 1985; Watanabe et al., 1987) in other macaques. In the cat retina, there is ample evidence that the cell composite of crossed and uncrossed projections in the nasotemporal overlap differs in terms of $\alpha(\mathrm{Y})$ cells, $\beta(\mathrm{X})$ cells and other cell types (W cells) (for details, see Stone, 1966; Stone and Fukuda, 1974; Kirk et al., 1976a, b; Illing and Wässle, 1981). This difference in the cell composite of the overlap region provides essential information for the functional understanding of the nasotemporal overlap and the differential roles of the cell types. Our results show that crossed projections from the temporal portion of the overlap arise mainly from $\mathrm{P} \alpha$ cells and $\mathrm{P} \gamma$ cells; uncrossed projections from the nasal portion arise mainly from $\mathbf{P} \beta$ cells.

Third, we sought physiological evidence of the nasotemporal overlap in the intact retina. By stimulating both sides of the LGN with electrical shocks, we recorded antidromic field potentials from a number of locations along the horizontal meridian in upper and lower retina within $8^{\circ}$ of vertical eccentricity. We obtained physiological evidence that: (1) the overlap is narrow around the fovea, gradually widening up to $3^{\circ}$ at $5 \mathrm{~mm}$ above or below the fovea, and (2) $\mathrm{P} \beta$ cell axons project ipsilatthe morphological studies.

These results suggest a candidate neural mechanism of $\mathrm{P} \alpha$ and $\mathrm{P} \beta$ cell systems through which primate binocular stereopsis along the midsagittal plane may be established. Certain lesions or defects in this binocular stereoscopic system may also give rise to macular sparing and splitting observed in clinical studies.

A short account of this work has been presented in abstract form (Fukuda et al., 1986). Since completion of the present study, a similar study on New World (Siamiri sciureus) and Old
World (Macaca fascicularis) monkeys has been reported (Leventhal et al., 1988).

\section{Materials and Methods}

A total of 11 Japanese monkeys (Macaca fuscata) were used in the present series of experiments: 6 monkeys (group I) were used for the study of retrograde labeling of ganglion cells with HRP, 3 monkeys (group II) for experiments with fluorescent tracers, and 2 (group III) for physiological experiments.

\section{Group I experiments}

Animals. Adult monkeys (AR 1-AR6) weighing 6.5-9.5 kg were used. Detailed accounts of animal preparation have been described previously (Fukuda et al., 1988). Briefly, the animals were anesthetized with ketamine hydrochloride $(10 \mathrm{mg} / \mathrm{kg}, \mathrm{i} . \mathrm{m}$.) and then with a gas mixture of halothane (1-2.5\%) and $\mathrm{N}_{2} \mathrm{O} / \mathrm{O}_{2}(70: 30)$ during surgery. Local anesthetic (2\% Xylocaine) was infiltrated into all pressure points and surgical wounds. The animals were immobilized with intravenous infusion of a mixture of gallamine-triethiodide $(15 \mathrm{mg} / \mathrm{kg} / \mathrm{hr})$, d-tubocurarine $(0.4$ $\mathrm{mg} / \mathrm{kg} / \mathrm{hr})$, and Nembutal $(1 \mathrm{mg} / \mathrm{kg} / \mathrm{hr})$ in a mixture of glucose and saline, and maintained under $\mathrm{N}_{2} \mathrm{O} / \mathrm{O}_{2}(70: 30)$ inhalation throughout the experiment. The expired $\mathrm{CO}_{2}$ concentration and electrocardiogram were monitored throughout the experiment, and body temperature was maintained at $38^{\circ} \mathrm{C}$ with a heating pad. Antibiotics were applied subcutaneously and also to the exposed dura.

Injection of HRP. Through a square hole made on the skull in the parietal region, several pairs of bipolar electrodes were inserted vertically into the left optic tract. The optic tract was located at AP 15-17, LM 6-9, and 30-32 $\mathrm{mm}$ deep from the cortical surface in Horsely-Clark's coordinates. Swish responses to visual stimuli were recorded through the bipolar electrodes, and for each recording site, the visual response field was plotted on a tangent screen placed $57.3 \mathrm{~cm}$ in front of the animal. We carefully located the sites that yielded visual reponses to hoth eyes so that the HRP would be injected into both crossed and uncrossed projections. The bipolar recording electrode was subsequently replaced by a $10 \mu \mathrm{l}$ microsyringe containing 30\% HRP (Sigma type IV) in 5\% DMSO. HRP was injected at 4-6 sites within the left optic tract of each animal; the electrode tip was minutely moved in the vertical direction during the $30 \mathrm{~min}$ injection period.

Histochemical reactions. After a survival time of $48-72 \mathrm{hr}$, the animal was deeply anesthetized with Nembutal and perfused with saline, and the retina was immediately removed and soaked for $10 \mathrm{~min}$ in $1 \%$ paraformaldehyde. The retina was then carefully dissected from the pigment epithelium in $0.1 \mathrm{~m}$ phosphate buffer, $\mathrm{pH}$ 7.3. After a brief rinse in the buffer, the retina was mounted flat on a gelatinized glass slide and postfixed in $2 \%$ glutaraldehyde for an additional hour under $5 \mathrm{gm}$ weight. The retinas of monkeys AR3-AR5 were histochemically reacted using the method of Hanker et al. (1977). In monkey AR2, the reaction-enhancing method with nickel and cobalt (Adams, 1981) was used, while in monkey AR6 the protocol of Leventhal et al. (1981) was used. Monkey AR1 died during the survival period, but its eyes were taken out immediately after death and processed as in monkeys AR3AR5.

In order to verify the extent of HRP injection sites, 3 monkeys (AR4AR6) were perfused with $1 \%$ paraformaldehyde and $2 \%$ glutaraldehyde, and the brain was dissected. Serial frontal sections were cut and reacted histochemically with 3,3'-diaminobenzidine (DAB) (Graham and Karnovsky, 1977). The sections were then mounted, dried, and counterstained with cresyl violet.

Quantitative analysis of HRP-labeled cells. After taking counts of the labeled cells in a $200 \times 200 \mu \mathrm{m}$ sauare at everv $500 \mu \mathrm{m}$ under a $\times 40$ isodensity maps of crossed and uncrossed projections by converting the cell count in each square into density. In one monkey (AR4), soma area was analyzed in the upper periphery where ganglion cells were well stained in both retinas contralateral and ipsilateral to the HRP injection. Using a camera lucida the outline of every labeled cell was drawn and the soma area measured by an image-analyzing system (Contron, Muto Kogyo).

In 3 monkeys (AR4-AR6) relative frequencies of $\mathrm{P} \alpha$ cells were studied in the upper retina contra- and ipsilateral to the HRP injection along the horizontal meridians at eccentricities of $5.0,7.5$, and $10 \mathrm{~mm}$ from the fovea. At each eccentricity, $\mathrm{P} \alpha$ cells were identified as having large 
soma and 3-4 thick primary dendrites (see Fig. 10) (Perry et al., 1984; Peichl et al., 1987). At eccentricities of 7.5 and $10 \mathrm{~mm}$, relative frequencies of large ganglion cells were examined in a $400 \times 400 \mu \mathrm{m}$ square at every $500 \mu \mathrm{m}$ along the horizontal meridian under magnification of $\times 20$; at an eccentricity of $5 \mathrm{~mm}$, a higher magnification $(\times 40)$ was used.

\section{Group II experiments}

Animals. Three adult monkeys (AR7-AR9) weighing from 3.5 to 6.7 $\mathrm{kg}$ were used. They were anesthetized and fixed to a stereotaxic apparatus as in group I experiments.

Injection of fluorescent dyes. In monkey AR7, $20 \mu \mathrm{l}$ of 5\% RITC was injected into the left LGN and $9 \mu \mathrm{l}$ of $10 \%$ DAPI was injected into the right LGN using $10 \mu \mathrm{l}$ microsyringes. The coordinates were AP 14, LM 7 , and 31-33 mm deep from the cortical surface. In the other 2 monkeys (AR8 and AR9), small pieces of gelatinized sponge (Sponzel) soaked with 10\% DAPI solution were implanted into the left LGN and those soaked with $5 \%$ RITC into the right LGN. Ising this method we consistently obtained better results in retrogradely labeling the ganglion cells, irrrespective of the fluorescent dyes used. To implant the piece of Sponzel, we first inserted it into the tip of a disposable venous catheter, then after fixating the outside holder and stereotaxically locating the needle tip within the LGN, slowly pushed the inner needle out, thus injecting the Sponzel deep within the LGN. The coordinates in AR8 and AR 9 were AP 7.0, LM 11-12, and 29-30 mm deep from the cortical surface, and AP 3.4-5.0, LM 11.0, and 28-29 mm deep, respectively.

Preparation of the retina. After 48-72 hr survival, the animals were perfused with saline from the left ventricle. Immediately after the perfusion, both eyes were removed, and the eye cups were soaked in $4 \%$ paraformaldehyde for $15 \mathrm{~min}$. The retinas were whole-mounted in 0.1 M phosphate buffer solution.

Ohservations under epifluorescence microscope. In each pair of the whole-mount retinas, retrogradely labeled ganglion cells were observed under an epifluorescence microscope (Nikon Optiphoto XF-EF). RITClabeled cells were observed under a green filter $(\mathrm{G}$; excitation wavelength, $580 \mathrm{~nm}$ ) and DAPI-labeled cells under an ultraviolet filter (UV; excitation wavelength, $330-380 \mathrm{~nm}$ ). Blood vessel patterns of each retina were first drawn on a sheet of paper under conventional microscope. The distributions of RITC- and DAPI-labeled cells were then drawn by consecutively sampling the retinal areas. Photomicrographs were taken to confirm the distribution patterns of both RITC- and DAPI-labeled cells. We did not analyze the cell density quantitatively in any of these retinas.

\section{Group III experiments}

Animals. Two adult Japanese monkeys (OH1 and $\mathrm{OH} 2)$ were anesthetized and maintained under artificial respiration as described in the preceding section

Stimulation of the $L G N$. Stimulating electrodes of bipolar tips were placed into the optic chiasm (OX), and the left and right LGNs. Photic responses of maximal amplitude werc obtained with the OX electrode in Horsely-Clark's coordinates at AP 20, LM 2, and $32 \mathrm{~mm}$ below the cortical surface. Adequate placement of the LGN electrodes was verified by monitoring typical postsynaptic waves induced by single $\mathrm{OX}$ shocks: When the electrode tip reached the surface of the LGN, a large negative wave (Bartlett et al., 1973) appeared; further deep into the magnocellular laminas, another negative wave of short latency appeared. In each monkey, the tip of the LGN electrode was carefully adjusted in between the parvo- and magnocellular laminas by recording both fast and slow potentials from the OX electrode (Schiller and Malpeli, 1978). The visual response field was then plotted on a tangent screen to further locate the tip of the stimulating electrode at the LGN site which represents the central visual fields of both contra- and ipsilateral eyes. Electrical pulses $70-170 \mu \mathrm{sec}$ with intensities below $100 \mathrm{~V}$ were applied to the OX and the LGN stimulating electrodes. The LGN elcetrode sites were verificd afterwards in Nissl-stained preparations.

Intraretinal recordings. Details of the intraretinal recordings have been given elsewhere (Fukuda et al., 1988). Essentially, glass microelectrodes filled with $3 \mathrm{M} \mathrm{KCl}$ were introduced stereotaxically into the eye through a small hole made on the sclera of the upper temporal quadrant. The eye was fixed to the frame of a stereotaxic apparatus with an eye ring; the guide cylinder for microelectrode insertion was held with a specially designed microelectrode holder (Narishige) that enabled minute nasotemporal or dorsoventral changes of the tip of the recording electrode while preventing inadvertent displacements of the eyeball. The cornea was protected with a contact lens that was prepared for each animal before the experiment. The power of the lens was adjusted so that the retinal image projected on the tangent screen would be focused. With light spots of various sizes, the visual response field of each recording site was plotted on the screen. The optic disk and fovea centralis was back-projected onto the same tangent screen by means of a reversible ophthalmoscope. Glass microelectrodes with impedances of 1 $5 \mathrm{M} \Omega$ were used. In one retina, the glass microelectrode was filled with pontamine sky blue in $2 \mathrm{M}$ sodium acetate solution to mark the recording sites.

After physiological recordings, the animals were perfused with saline followed by $4 \%$ paraformaldehyde under deep anesthesia with Nembutal. The eyes were enucleated and whole-mount retinas were prepared. The retinas were stained with $0.5 \%$ cresyl violet and dehydrated with graded alcohols. Using the same method as described above for HRPlabeled cells, an isodensity map of the whole-mount retina was made from one of the Nissl-stained retinas of $\mathrm{OH} 1$.

\section{Results}

\section{Extent of HRP and fluorescent dye injections}

$H R P$-injection. Of the 6 monkeys used, unilateral HRP injections into the optic tracts were successful in monkeys AR4-AR6 and whole-mount preparations of each pair of retinas were studied; thus, most of the data presented below are based on the data from these 3 monkeys. The first monkey (AR1) died during the survival period, but both of its retinas were processed histochemically. With the second monkey (AR2), only the retina ipsilateral to the injection was studied using Adams' method (1981). In the third monkey (AR3), only an incomplete distribution pattern of HRP-labeled cells was obtained. Nevertheless results obtained from these monkeys confirmed those obtained from AR4-AR6.

In 4 monkeys-AR 1, and AR4-AR6-the extent of HRP injections was examined in sections of the brain counterstained with cresyl violet. In each case, several large reaction spots covered the whole extent of the left optic tract. Light brown areas surrounding the reaction spots extended to a wide area of the thalamus and in some cases even to the inferior colliculus. Except for occasional labelings of suprachiasmatic decussation fibers, HRP reaction products did not extend into the other hemisphere nor into the uninjected optic tract. From these observations we concluded that no single fiber on the other side of the optic tract had taken up HRP.

Fluorescent dyes. In 2 monkeys (AR8 and AR9), we confirmed the injection sites of RITC and DAPI in the LGN and the optic tract. In AR8, the center of RITC injection was in the rostromedial part of right LGN; DAPI injection was centered at the rostral pole of left $L G N$ and its neighboring optic tract, extending into the lateral half of left rostral LGN. In AR9, RITC injection was localized along the border region between the right optic tract and rostral LGN; another focus was also found in the medial half of right LGN. DAPI injection covered the border region between the left optic tract and $L G N$, and 2 clear focal areas were found in the medial half of left LGN.

\section{Nasotemporal overlap: central to peripheral widening and asymmetric distribution of ganglion cells}

Figure 1 shows photomicrographs of 1 of the 3 pairs of wholemount retinas from AR4-AR6. The HRP-labeled ganglion cells are largely distributed in one hemiretina, with the border along the vertical meridian; however, the decussation line is not straight, and both crossed and uncrossed projections extend 

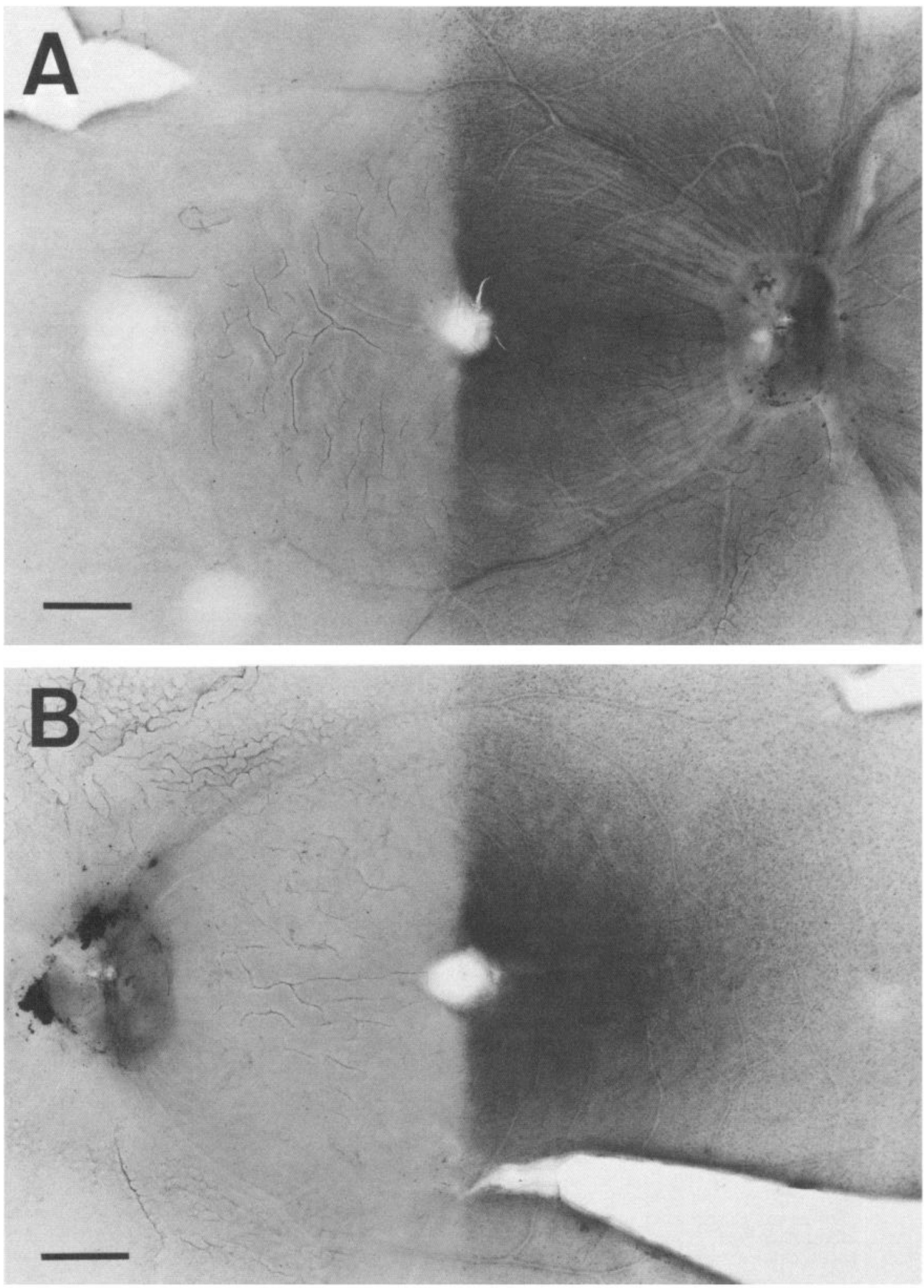

Figure 1. Photomicrographs of whole-mount retinas of monkey AR5. $A$, Contralateral; $B$, ipsilateral to the HRP injection. Nasal $(A)$ and temporal $(B)$ hemiretinas are completely labeled. Note, however, that in both retinas the border of the distribution of HRP-labeled ganglion cells slightly extends towards the unlabeled hemiretina. Also note that the extension gradually increases in width above and below the fovea. Scale bars, $1 \mathrm{~mm}$. 

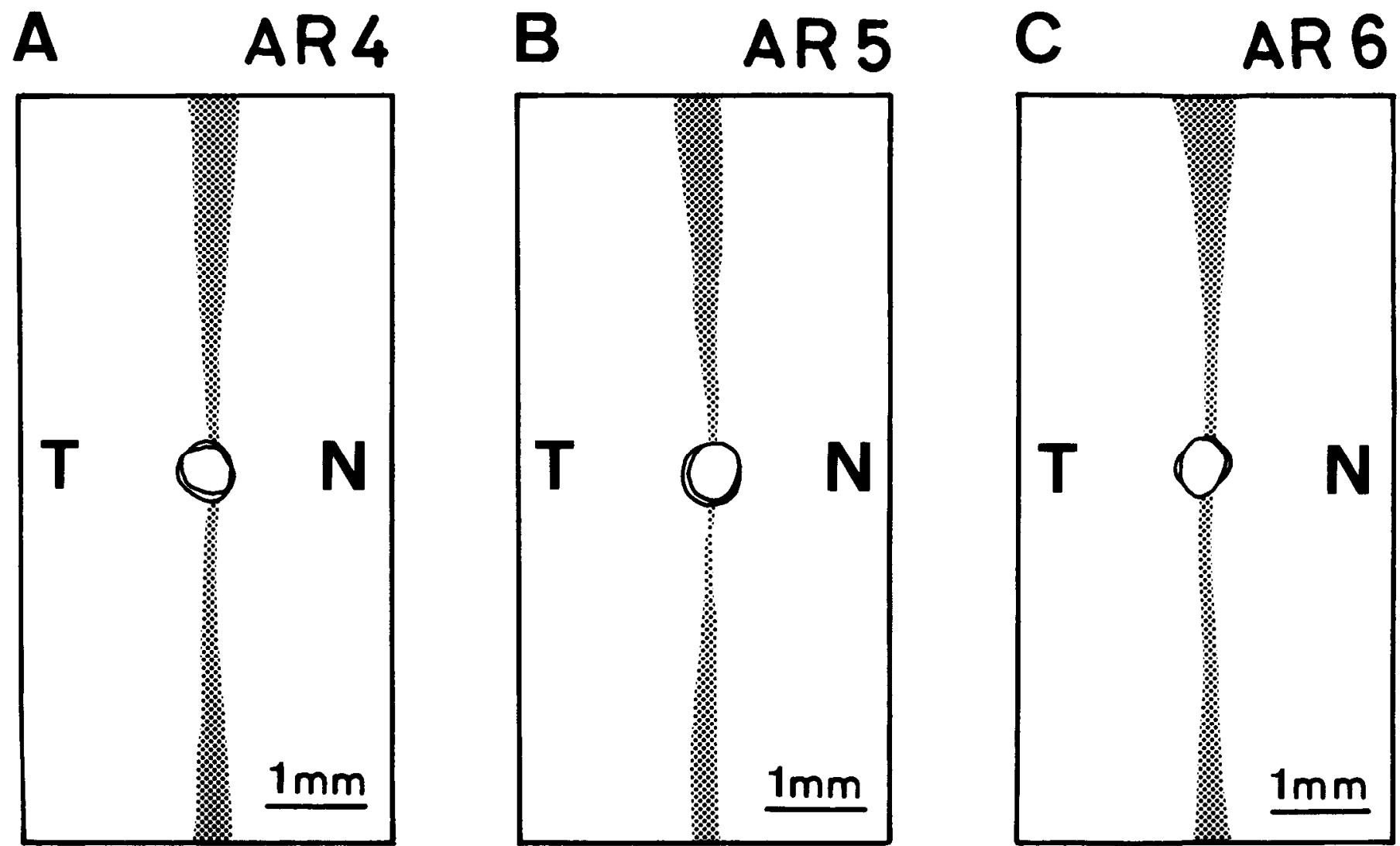

Figure 2. Schematic drawings of the width of the nasotemporal overlap along the vertical midline in 3 monkeys, AR4-AR6. The drawings were constructed from photomicrographs as shown in Figure 1, $A, B$ (refer to Stone et al., 1973); in brief, by overlaying the foveal circle of the paired retinas, the outline drawing of the temporal edge of the contralaterally projecting cells was superimposed on the reversed drawing of the nasal edge of the ipsilaterally projecting cells. In each of the 3 cases, the width of the overlap increases from the fovea towards upper and lower retinas; the overlap is slightly but consistently wider in the upper retina than in the lower one. Note that in AR4 and AR6 the vertical axis of the nasotemporal overlap passes through the fovea slightly off the vertical midline towards the nasal hemiretina.

slightly into the other hemiretina. The shaded overlap regions shown in Figure 2 were obtained from each pair of retinas by superimposing the foveal circle of one retina on that of the leftto-right inverted other retina. Assuming that $1 \mathrm{~mm}$ in the monkey retina corresponds to $4^{\circ}$ in visual angle (Rolls and Cowey, 1970; Perry and Cowey, 1985), the estimated width of the overlap in all 3 cases was only $0.6^{\circ}$ or a little less at the central retina, gradually increasing towards the upper and lower periphery. At $3.7 \mathrm{~mm}$ above the zero horizontal meridian, the widths of the overlap obtained from AR4-AR6 were $2.1^{\circ}, 1.8^{\circ}$, and $2.7^{\circ}$, respectively; at $3.7 \mathrm{~mm}$ below the meridian, they were $1.6^{\circ}, 1.2^{\circ}$, and $1.5^{\circ}$, respectively. In all 3 cases, the overlap was wider in the upper retina than in the lower retina.

This widening of the nasotemporal overlap towards the periphery was confirmed in the retinas of the other 3 monkeys labeled by fluorescent dyes. Figure 3 shows the results obtained from AR7 (Fig. 3, $A, B$ ) in the peripheral retina and AR8 (Fig. $3, C, D)$ in the central third of the retina. A wide overlap region of about $12^{\circ}$ is apparent in the distributions of contralaterally projecting RITC-labeled cells (red dots) and ipsilaterally projecting DAPI-labeled cells (blue dots) in the upper peripheral retina (Fig. 3, $A, B$ ). By contrast, the central overlap within 3 $\mathrm{mm}$ below the fovea is narrow (Fig. 3, $C, D$ ) and less than 1 $\mathrm{mm}$, or $4^{\circ}$, when measured under a fluorescent microscope.

Figure 4 contrasts photomicrographs of RITC- and DAPIlabeled cells taken in the same locations at $0.5 \mathrm{~mm}$ above (Fig.
$4, A, B$ ) and $5 \mathrm{~mm}$ above (Fig. $4, C, D$ ) the fovea in the wholemount retinas of AR9. RITC was injected into the right $L G N$ (Fig. 4, $A, C$ ); DAPI was injected into the left LGN (Fig. 4, $B$, $D$ ). Here again, in the central region the overlap is very narrow (Fig. 4, $A, B$ ), while further away from the fovea RITC- and DAPI-labeled cells intermingle extensively (Fig. 4, C, D). This trend continues up to the peripheral regions of AR9. Figure 5, $C, D$, presents schematically drawn enlargements of the overlap in the fan-shaped striped areas of right (Fig. 5A) and left (Fig. $5 B$ ) whole-mounts of AR9. They clearly show that the widths of the overlaps in both retinas are quite narrow within $1.5 \mathrm{~mm}$ above the fovea, gradually increasing towards the upper periphery. This is consistent with the data obtained from HRP experiments (see Fig. 2). With these fluorescent dye experiments, however, the exact border of the overlap in the central retina was obscured because in both retinas, DAPI-labeled cells (blue dots) extended more dominantly into the unlabeled hemiretinas than the RITC-labeled cells (red dots) whether they were crossed or uncrossed projections. This may be due to less uptake of RITC than DAPI, and/or to brighter fluorescence of DAPIlabeled cells.

In isodensity maps of HRP-labeled ganglion cells of 2 monkeys, AR4 (Fig. 6) and AR5 (Fig. 7), a clear asymmetric distribution of crossed and uncrossed projections along the vertical meridian was observed in addition to the widening of the overlap towards the periphery. The vertical border of the crossed 

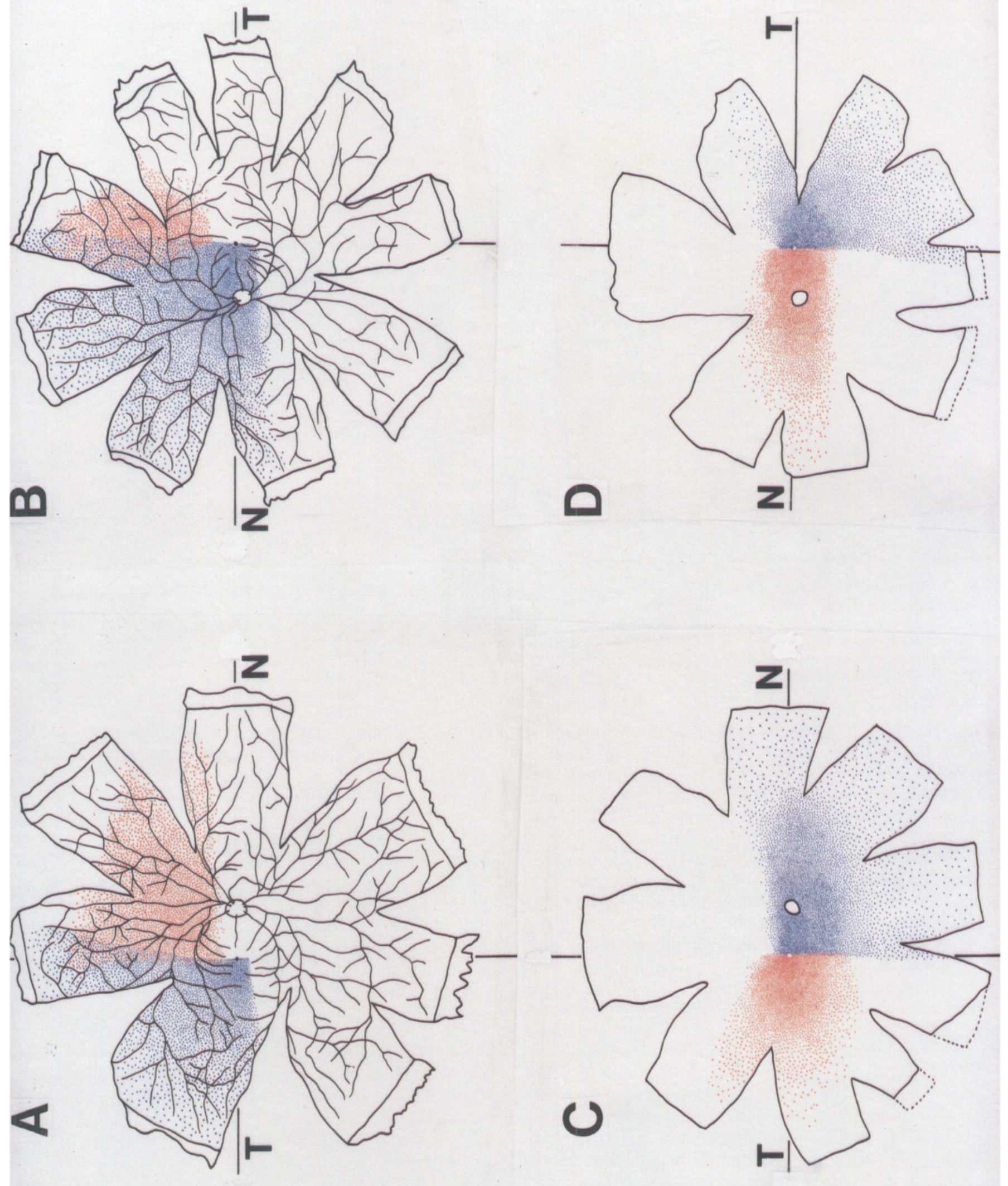

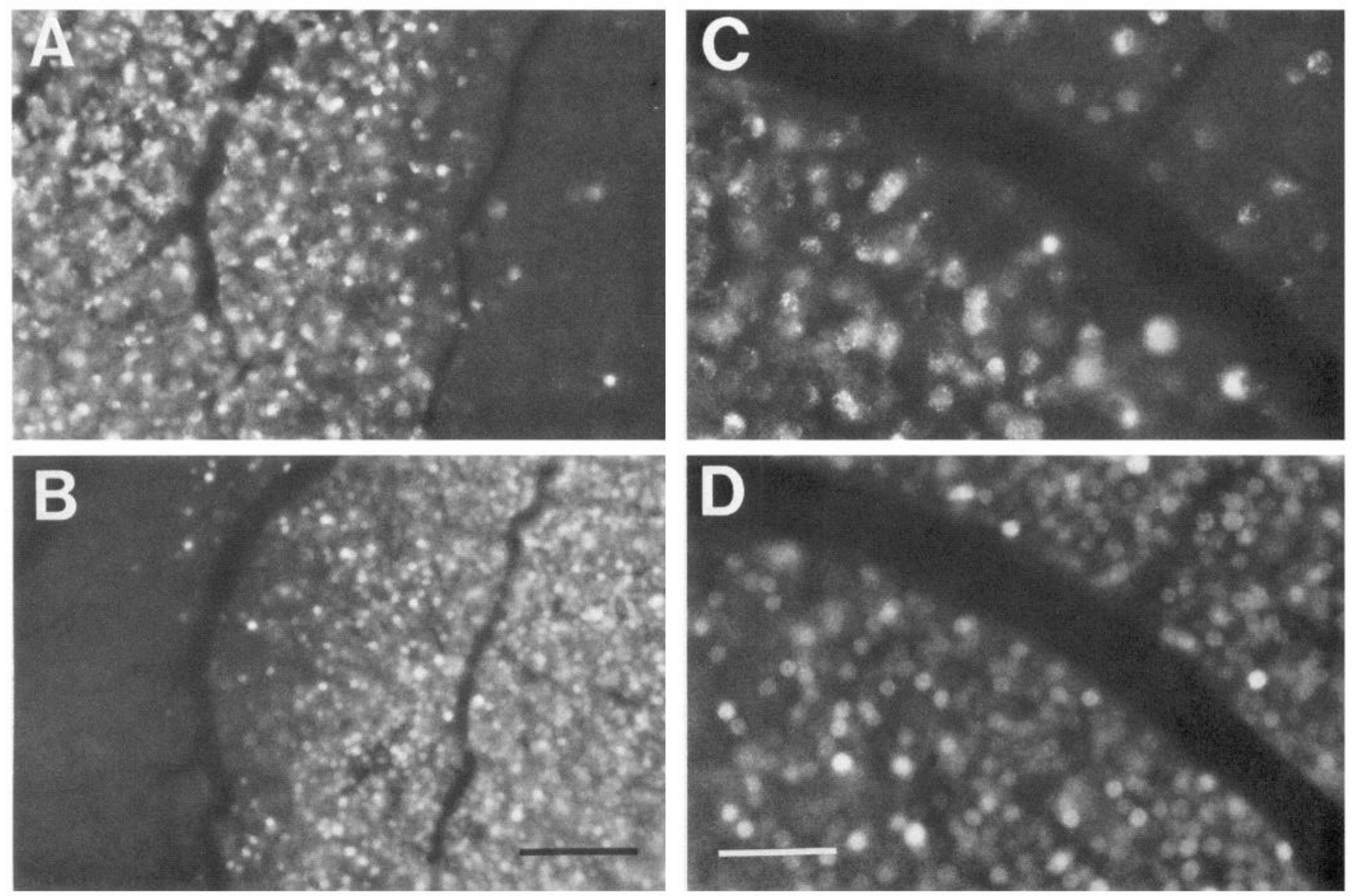

Figure 4. Photomicrographs of fluorescent dye-labeled ganglion cells in monkey AR9. $A$ and $B$, Distributions of RITC-and DAPI-labeled ganglion cells, respectively, in the same location centered at $1.5 \mathrm{~mm}$ above the fovea. $C$ and $D$, Distributions of RITC- and DAPI-labeled cells, respectively, in the same location centered at $5 \mathrm{~mm}$ above the fovea. Note that in central retina $(A$ and $B)$, the nasotemporal overlap is much narrower than that in the periphery $(C$ and $D$ ), which overlaps completely. Scale bars, $100 \mu \mathrm{m}$.

projection is fairly straight from the central up to the peripheral retina: In the retina contralateral to the HRP injection (Figs. 6, 7), the isodensity lines of 0.05 and $0.1 \times 10^{3} / \mathrm{mm}^{2}$ are quite parallel to the zero vertical meridian except for a small depression around the fovea. Ipsilaterally projecting cells, on the other hand, extend further into the nasal hemiretina in the upper and lower peripheries. To estimate the width of the overlap, we defined the distance from the vertical meridian to the vertical isodensity line of $0.05 \times 10^{3} / \mathrm{mm}^{2}$ at the overlap border as the horizontal width of the overlap in the nasal and temporal retina. In Figure 6 the horizontal width of the nasal overlap portion was $2.7 \mathrm{~mm}$ at $12 \mathrm{~mm}$ above the zero horizontal meridian, and $1.2 \mathrm{~mm}$ at similar eccentricity in the lower retina. The width of the temporal portion of the overlap is narrower than that in the nasal portion: less than $1 \mathrm{~mm}$ in both upper and lower retinas. Combining both temporal and nasal portions of the overlap, the total width of the overlap in AR4 would cover visual angles of $14.8^{\circ}$ across the zero vertical meridian in the upper retina and $8.8^{\circ}$ in the lower retina. In AR5, we estimated the maximal overlap to be $15^{\circ}$ in the upper periphery and $5^{\circ}$ in the lower periphery. In both AR4 and AR5, the overlap width is wider in the upper retina than in the lower retina.

The asymmetry in the distribution pattern of crossed and uncrossed retinal ganglion cell projections in the nasal and temporal portions of the peripheral overlap was also verified in fluorescent dye experiments. In both left and right retinas, ipsilaterally projecting DAPI-labeled cells (Fig. $3 A$, blue dots) or RITC-labeled cells (Fig. $3 B$, red dots) in the upper temporal retinas extended further towards the nasal hemiretina compared with that of the contralaterally projecting RITC-labeled cells (Fig. $3 A$, red dots) or DAPI-labeled cells (Fig. $3 B$, blue dots), which extended only slightly towards the temporal retinas.

$\leftarrow$

Figure 3. Distribution patterns of ganglion cells retrogradely labeled with 2 fluorescent dyes, DAPI and RITC, in monkey AR7 $(A$ and $B)$ and AR8 $(C$ and $D)$. Ganglion cells labeled with RITC and DAPI are drawn with red and blue dots, respectively. Right $(A$ and $C)$ and left $(B$ and $D)$ retinas from each animal are presented. In AR7, DAPI was injected into the right LGN and RITC into the left LGN. In AR8, RITC was injected into the right LGN and DAPI into the left LGN. There is a clear overlap in the upper peripheral retina of $A$ and $B$ in AR7. In AR8, $C$ and $D$, the overlap in the central part of the retina is quite narrow. 
A
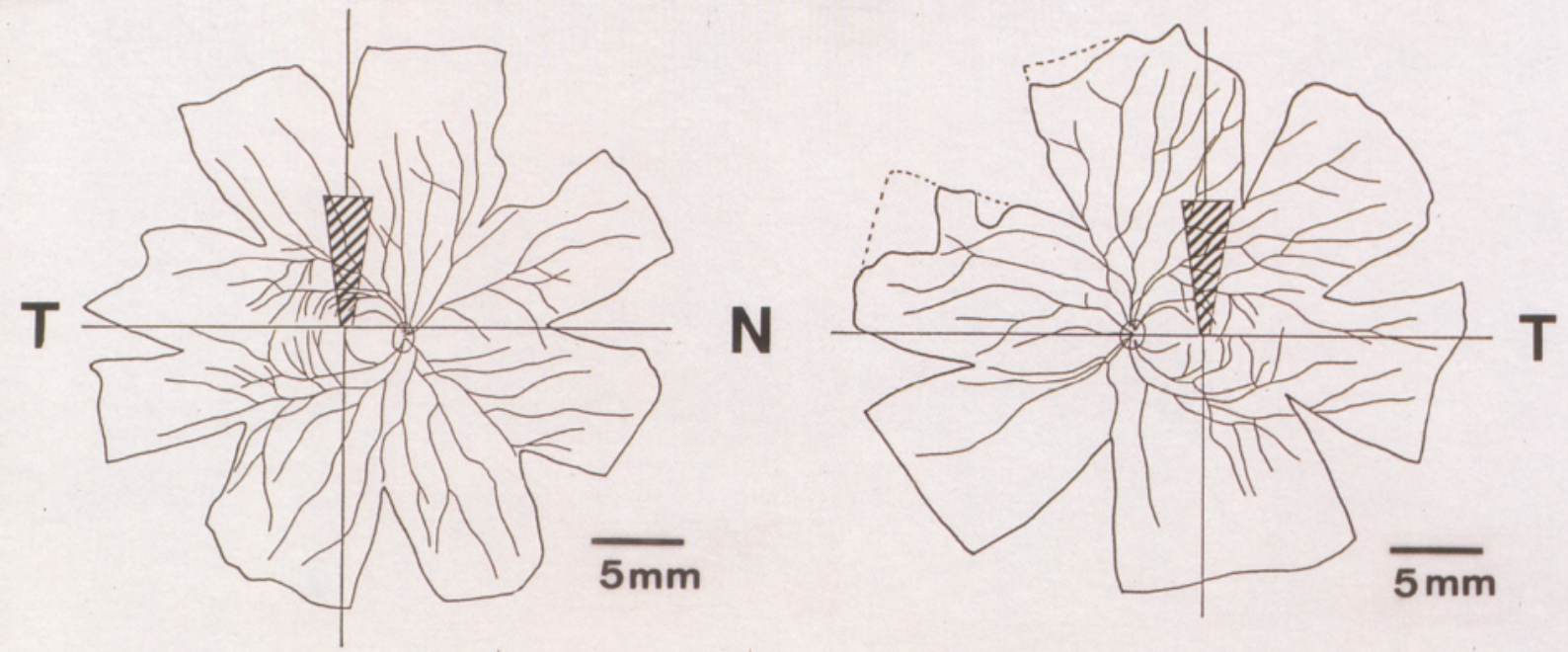

C

D
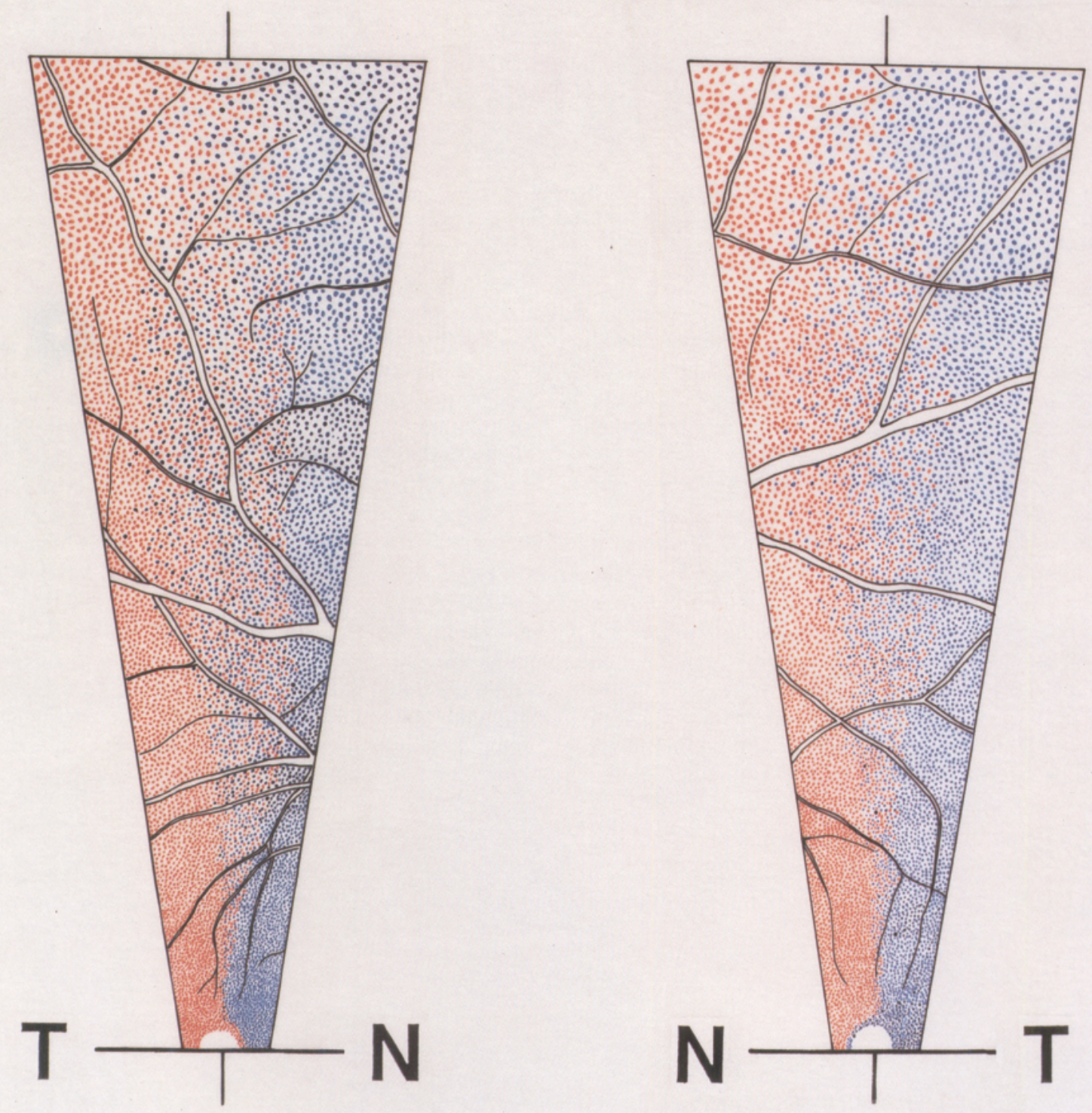
AR 4

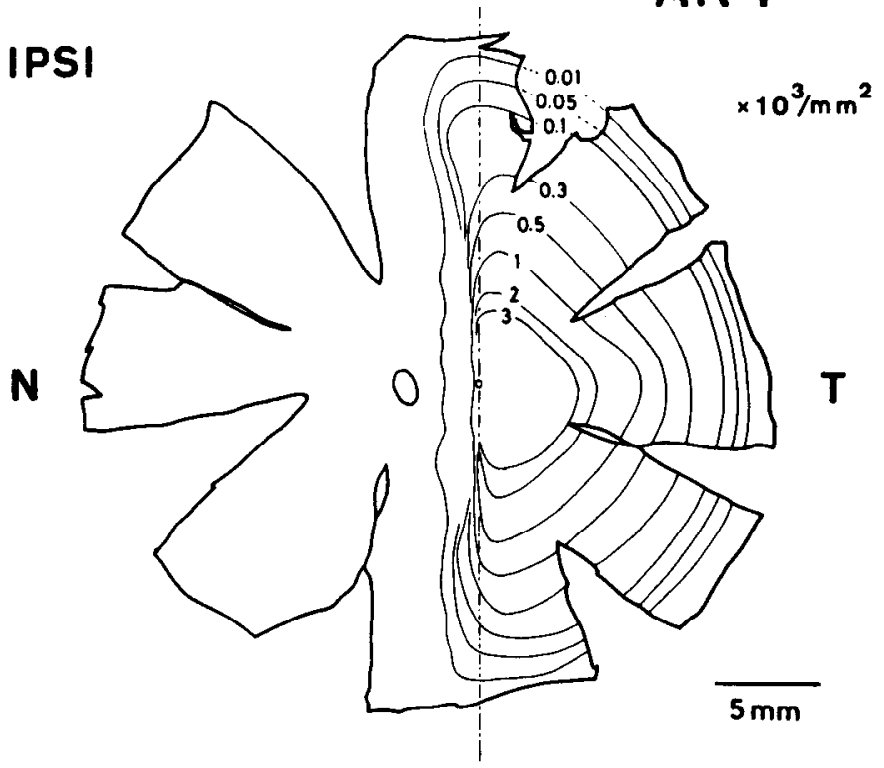

\section{CONTRA}

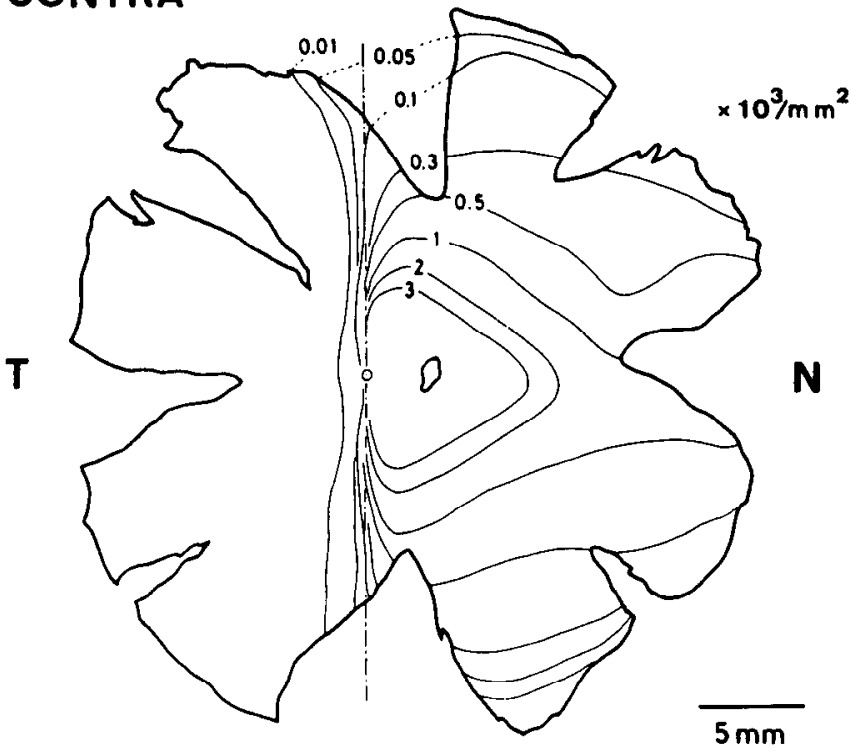

Figure 6. Isodensity maps of HRP-labeled ganglion cells of retinas of AR4 ipsilateral (IPSI) and contralateral (CONTRA) to the injection. The vertical midline is shown by a dashed line. Note a clear extension of ipsilaterally projecting cells into nasal $(N)$ retina and that of contralaterally projecting cells into temporal $(T)$ retina. In the ipsilateral retina, the extension of HRP-labeled cells increases in upper and lower retinas at vertical eccentricities of more than $5 \mathrm{~mm}$. By contrast, in the contralateral retina, the extension is only slight and relatively uniform from central retina to the upper and lower periphery. The density lines of the crossed projection in nasal retina are elongated horizontally, whereas the density gradient of the uncrossed projection is roughly radially symmetrical in temporal retina.
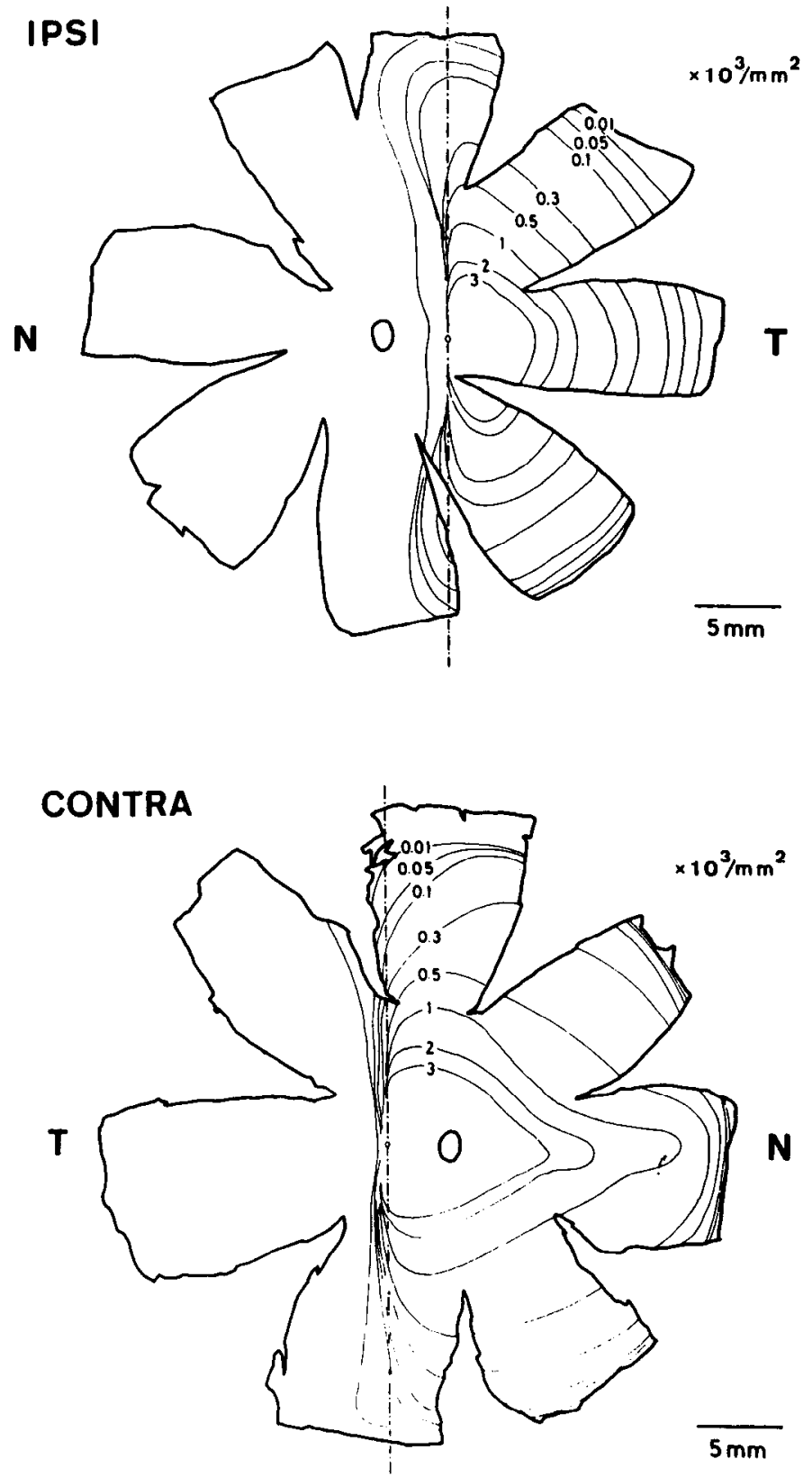

Figure 7. Isodensity maps of HRP-labeled ganglion cells in wholemounts of AR5 ipsilateral (IPSI) and contralateral (CONTRA) to the injection. The conventions are the same as those in Figure 6. The distribution patterns of uncrossed and crossed projections are similar to those of monkey AR4 given in Figure 6.

Figure 5. Schematic drawings of right $(A)$ and left $(B)$ retinas of AR9. RITC was injected into the right LGN, and DAPI into the left LGN. $C$ and $D$, Enlargements of the nasotemporal overlap of DAPI-labeled cells (blue dots) and RITC-labeled cells (red dots) in the fan-shaped areas indicated with shadings in $A$ and $B$. Note that in both retinas the overlap of DAPI- and RITC-labeled cells, that is, the nasotemporal overlap, increases in width towards the upper periphery. Also note a clear asymmetry in the distribution of these cells around the fovea centralis of both retinas. 

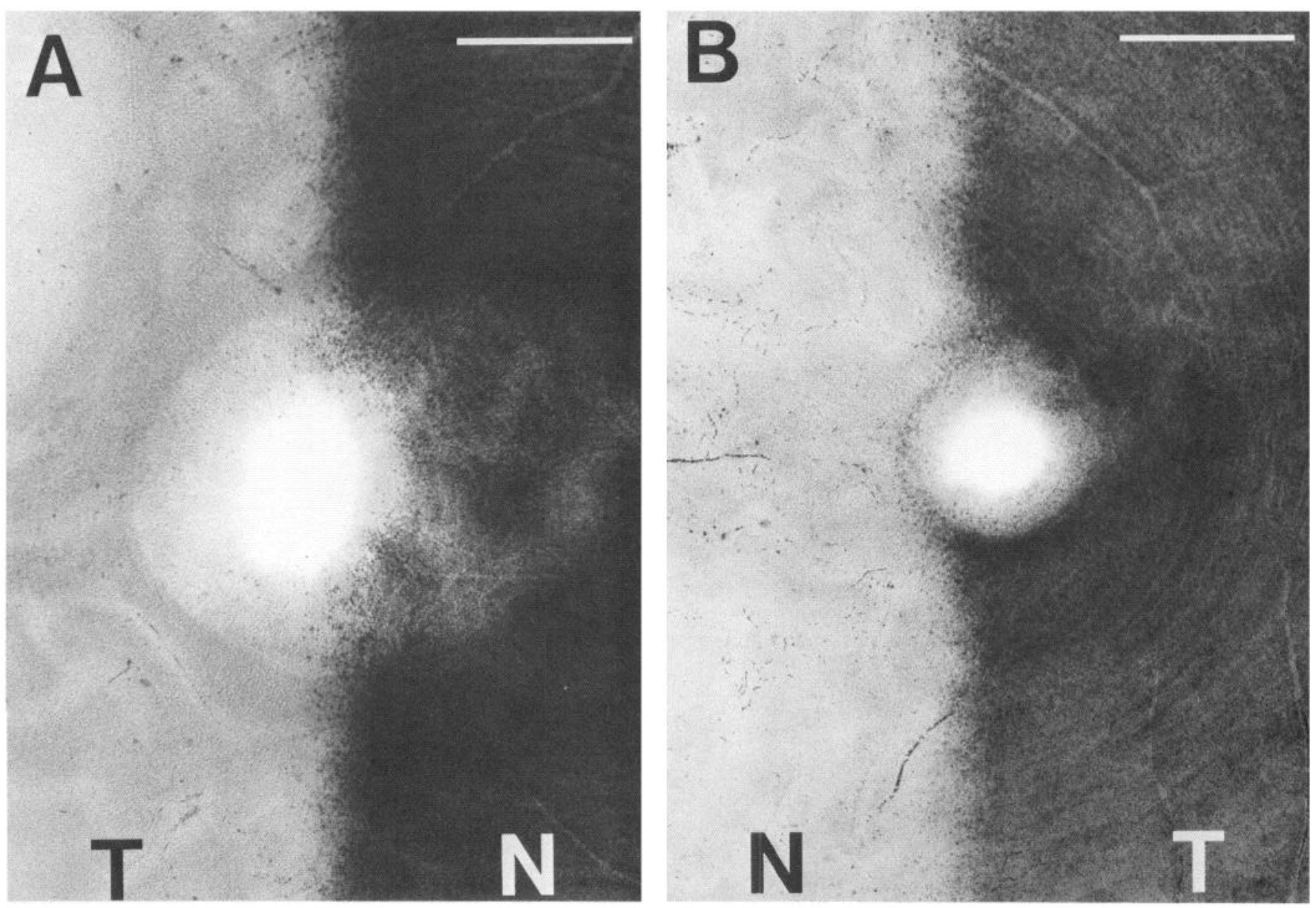

Figure 8. Photomicrographs of central retina of monkey AR4 under higher power. $A$, The retina contralateral to the HRP injection; $B$, ipsilateral retina; $T$, temporal; $N$, nasal. Note that in $B$, HRP-labeled cells encircle the nasal edge of the fovea centralis, while no such trend is apparent in $A$. Scale bars, $500 \mu \mathrm{m}$.

\section{Nasotemporal overlap: perifoveal asymmetry}

Two asymmetric features in HRP labeling were noted in the foveal regions of retinas contra- and ipsilateral to the injection. First, labeled cells in the ipsilateral retina (Fig. $8 B$ ) encircle the perifoveal region of the nasal retina, whereas the labeled cells in the contralateral retina (Fig. $8 A$ ) are clustered only along the nasal edge and do not invade into the temporal retina. Second, the vertical meridian of ipsilaterally projecting cells just above and below the fovea is slightly shifted off the center of the fovea into the nasal hemiretina (Fig. $8 B$ ). Conversely, the vertical meridian of the contralaterally projecting cells appears to be shifted towards the nasal hemiretina (Fig. $8 A$ ).

These asymmetries are more clearly shown in outline drawings of the labeled cells of AR4 (Fig. 9). We consistently observed that the ipsilaterally projecting cells completely encircled the fovea centralis. This was true in monkeys AR5 and AR6, as well as in other monkeys with incomplete HRP injections (AR1AR3). However, the nasal shift of the midline of the nasotemporal overlap observed in AR4 and AR6 was not as obvious in AR5 (see Fig. 2). Slight distortions of the foveal pit during the histological process of whole-mount preparation may have obscured the nasal shift in the latter case. By reversing the drawing of one retina and overlaying the center of the fovea on that of the other drawing in Figure 9, we estimated the width of the nasotemporal overlap at the foveal region to be about $1^{\circ}-1.5^{\circ}$ in AR4; the estimated values were similar in drawings from AR5 and AR6.

We confirmed the asymmetric distribution of crossed and uncrossed projections around the fovea in all 3 monkeys injected with fluorescent dyes (AR7-AR9). Figure 5, $C, D$, clearly indicates the asymmetric distributions of RITC- and DAPI-labeled cells around the fovea in both retinas of AR9.

\section{Identification of HRP-labeled cells}

Figure 10 shows a photomicrograph of HRP-labeled cells in the upper peripheral retina $(9.5 \mathrm{~mm}$ above the zero horizontal meridian) of AR5 contralateral to the HRP injection. Nine large ganglion cells with soma diameter of over $20 \mu \mathrm{m}, 3-4$ thick primary dendrites, and large dendritic fields were identified as $\alpha \mathrm{M}$ cells (Suyama, 1986), that is, P $\alpha$ cells (Perry and Cowey, 1984; Perry et al., 1984), A cells (Leventhal et al., 1981), or parasol cells (Rodieck et al., 1985, 1987; Watanabe et al., 1987). The majority of the other cells had medium-sized somas (12$15 \mu \mathrm{m})$, one primary dendrite, and small dendritic fields. Most of them are probably $\beta \mathrm{M}$ cells of Suyama (1986) or midget cells of Rodieck et al. (1985), corresponding to $\mathrm{P} \beta$ cells of Perry et al. (1984) or to B cells of Leventhal et al. (1981). Yet other cell types with small somas $(\leqq 12 \mu \mathrm{m})$ or medium-sized to large somas (14-18 $\mu \mathrm{m})$ and several fine primary dendrites known as 


\section{CONTRA}

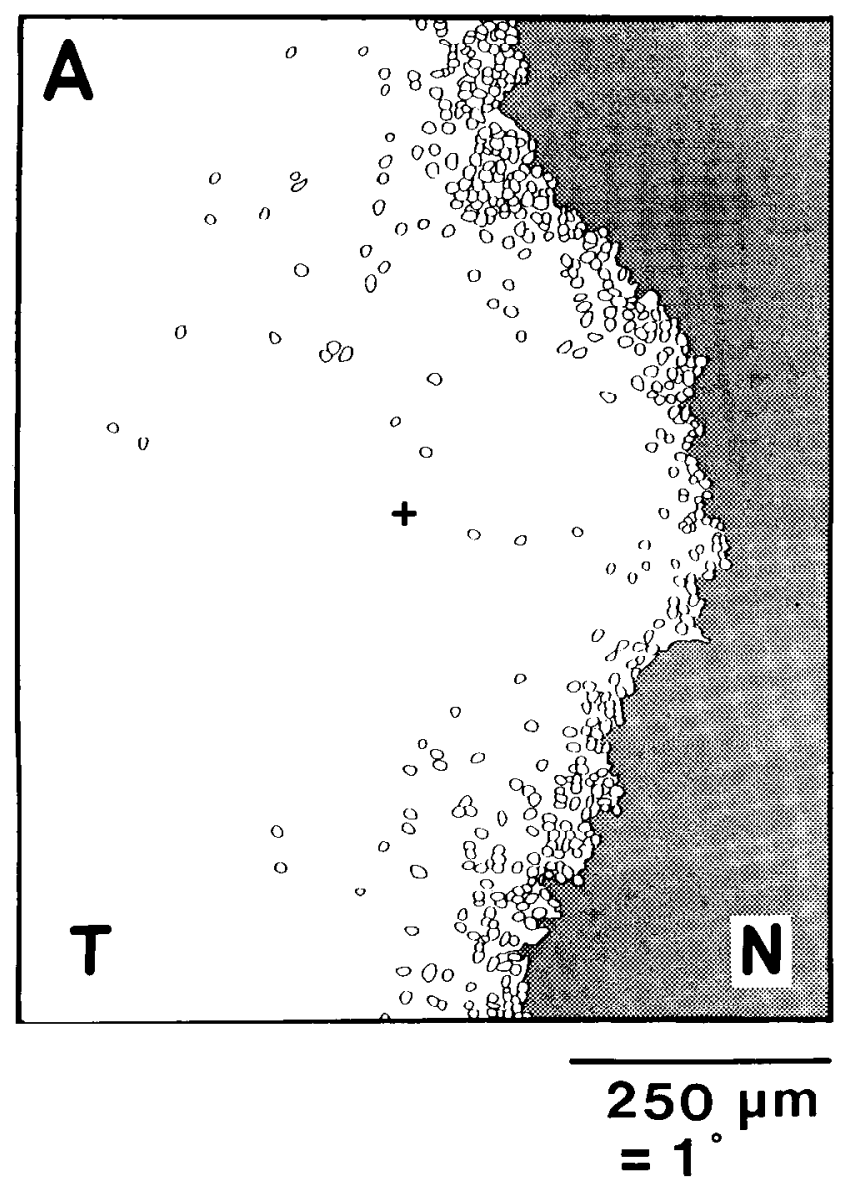

IPSI

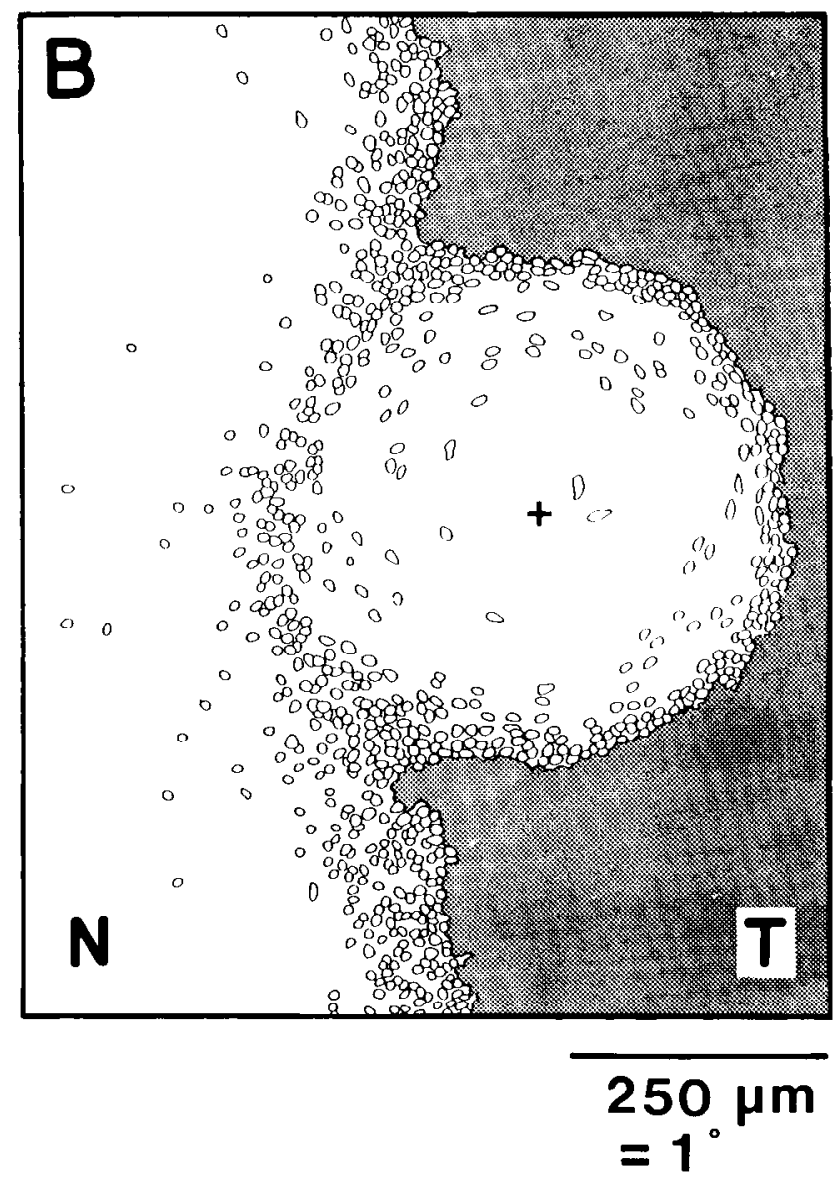

Figure 9. Distribution patterns of contralaterally $(A)$ and ipsilaterally $(B)$ projecting ganglion cells around the fovea centralis. The HRP-labeled cells were drawn under higher magnification and later contracted. Shaded areas on the right represent the area where all ganglion cells are labeled with HRP. The center of the fovea centralis is indicated (+). $T$, Temporal; $N$, nasal. Note that the nasal border of the labeled cells in $B$ run vertically, slightly off the center of the foveal pit towards nasal retina.

$\gamma \mathrm{M}$ cells (Suyama, 1986), $\mathrm{P} \gamma, \mathrm{P} \delta$, and $\mathrm{P} \epsilon$ cells (Perry and Cowey, 1984; Perry et al., 1984) or C, D, and E cells (Leventhal et al., 1981) were also visible. However, many labeled cells with medium-sized to small somas were not completely filled with HRP so that unequivocal classification was not always possible.

The general impression was that labeling of dendrites with HRP was better in cells located in the upper retina than those in the lower retind; it is unclear whether this is related to the HRP injection method. In the otherwise unlabeled hemiretina, some large ganglion cells were stained nonspecifically using Adams' (1981) or Leventhal et al.'s (1981) methods. However, these cells were clearly distinguished from HRP-labeled cells.

\section{Soma size of ganglion cells in the nasotemporal overlap}

The soma size of HRP-labeled cells varied across the nasotemporal overlap. For contralaterally projecting cells, the soma size bccame larger the farther into temporal retina the labeled cell was located, that is, soma size increased as ganglion cell density decreased in the overlap zone. For ipsilaterally projecting ganglion cells, the soma size became smaller the farther into nasal retina the labeled cell was found, that is, soma size decreased as cell density decreased in the overlap zone.
Figure $11 \mathrm{~A}$ is a drawing of all the labeled cells in the contralateral retina of AR4 within a $1.88 \times 2.2 \mathrm{~mm}$ square centered at the zero vertical meridian $8 \mathrm{~mm}$ above the fovea. In the nasal retina, labeled cells had large, medium-sized, and small somas, whereas in the temporal retina, they had mostly large or small somas. Soma size distributions in the nasal and temporal retinas are given in histograms (Fig. $11, B, C$ ). In the histogram of the nasal retina (Fig. $11 C$ ), $17.4 \%$ were large ganglion cells, presumably $\mathrm{P} \alpha$ cells (with soma area larger than $280 \mu \mathrm{m}^{2}$ ), the rest were small to medium-sized cells with their peak at $140 \mu \mathrm{m}^{2}$. By contrast, the proportion of large cells ( $\mathrm{P} \alpha$ cells) was $36.6 \%$ in the temporal retina, and the peak of small to medium-sized cells was at $100 \mu \mathrm{m}^{2}$. This shift in the peak distribution in the temporal retina is most probably due to the relative increase of small cells and decrease of medium-sized cells. At higher magnification under microscope, no small cells revealed dendritic morphologies of $\mathrm{P} \beta$ cells; instead, most of them showed 2-3 thin elongated dendrites characteristic of $\mathrm{P} \gamma$ cells.

Figure $12 A$ shows drawings of ipsilaterally projecting ganglion cells in a square of the upper retina of AR4 with the same area and at the same eccentricity as the one in Figure $11 \mathrm{~A}$. From the vertical midline into the nasal retina there is a clear decrease in 
Figure 10. Photomicrograph of HRPlabeled ganglion cells at $9.5 \mathrm{~mm}$ from the fovea centralis in upper nasal retina contralateral to the injection. Large ganglion cells are characterized by large somas ( $>20 \mu \mathrm{m}$ in diameter) and 3-4 thick primary dendrites that extend radially (a typical example is indicated by the arrow), consistent with the morphology of $\alpha \mathrm{M}$ cells of Suyama (1985), or P $\alpha$ cells of Perry et al. (1984), A cells of Leventhal et al. (1981), and parasol cells of Rodieck et al. $(1985,1987)$. Scale bar, $100 \mu \mathrm{m}$.

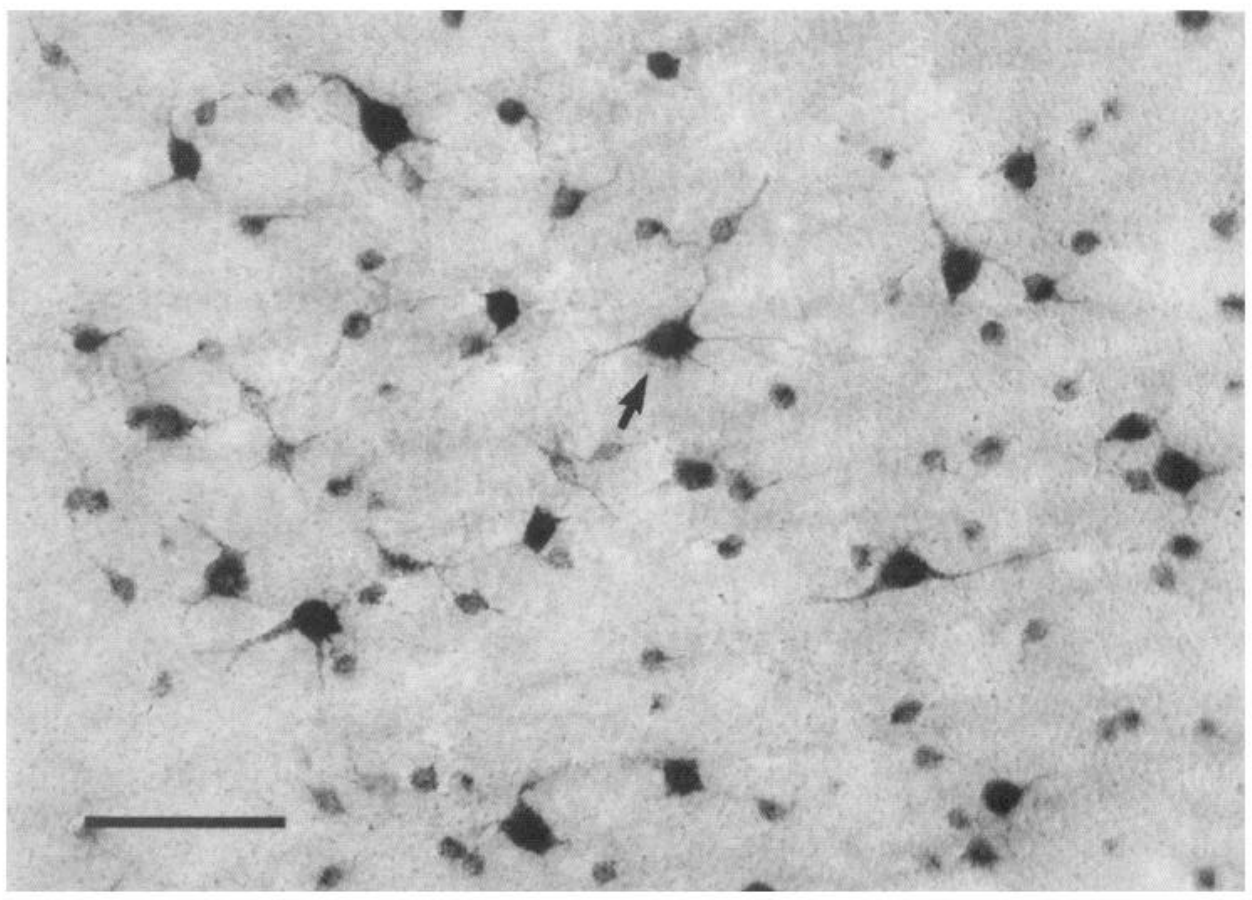

the proportion of large cells with large thick dendritic extensions, characteristic of $\mathrm{P} \alpha$ cells; most of the labeled cells have mediumsized soma (12-15 $\mu \mathrm{m})$ and only one thick primary dendrite. At higher magnification, most of the well-labeled cells were identified as $\mathrm{P} \beta$ cells (Perry et al., 1984). However, there are also a few cells with medium-sized to large somas (14-18 $\mu \mathrm{m})$ with several fine primary dendrites, which probably correspond to $\mathrm{P} \epsilon$ celis or E cells (Leventhal et al., 1981; Perry and Cowey, 1984). In the soma size histogram, large cells with a soma area of more than $280 \mu \mathrm{m}^{2}$ occupied only $1.3 \%$ of the total population in the nasal portion compared with $6.8 \%$ in the temporal portion. The peak at $150 \mu \mathrm{m}^{2}$ is much sharper in the nasal portion (Fig. 12B) than that in the temporal portion (Fig. 12C).

\section{Relative frequency of large ganglion cells}

The proportion of large ganglion cells, presumably $\mathrm{P} \alpha$ cells, having crossed axon projections, gradually increased on moving from the nasal into the temporal portion of the overlap (Fig. 11). Conversely, in the uncrossed projection (Fig. 12), the proportion of large cells sharply decreased towards the nasal retina. To determine whether these tendencies were consistent at all eccentricities of the overlap, we systematically examined the proportion of $\mathrm{P} \alpha$ cells in the labeled cell population at 5, 7.5, and $10 \mathrm{~mm}$ above the fovea in AR4-AR6. P $\alpha$ cells were identified as having large somas and 3-4 thick primary dendrites under high magnification (see Fig. 10) (Perry et al., 1984; Peichl et al., 1987). For contralaterally projecting cells (Fig. 13), the proportion of $\mathrm{P} \alpha$ cells was $7-15 \%$ in nasal retina. This gradually increased towards the vertical midline and was at its maximum in the temporal portion of the overlap in all 3 monkeys. For the ipsilaterally projecting cells (Fig. 14), the proportion of $\mathrm{P} \alpha$ cells gradually decreased from $10-20 \%$ in temporal retina to near $0 \%$ in the nasal retinal portion of the overlap. Each eccentricity in all 3 cases showed a similar pattern.

In both contra- and ipsilateral retinas, changes in the proportion of $\mathrm{P} \alpha$ cells corresponded to the decrease in the density of the total labeled ganglion cells at the nasal or temporal edge of the overlap. Because of slight distortions in the peripheral retinas due to incisions when making whole-mount preparations, the midpoint of the decline in the total ganglion cell density was not always centered at the vertical midline. Nevertheless, there is a clear correspondence between the decrease or increase in the proportion of $\mathrm{P} \alpha$ cells and the decrease in total cell density at every level above the fovea.

The proportion of $\mathrm{P} \alpha$ cells in the uncrossed projection is quite low into the nasal portion of the overlap. This means that uncrossed projections from the nasal retina must arise from $\mathrm{P} \beta$ and other medium-sized to small cells, since each ganglion cell projects to either the ipsi- or contralateral optic tract. ${ }^{3}$ Further, according to Perry et al. (1984), $\mathrm{P} \beta$ cells outnumber other medium-sized to small cells by a factor of 8 , which means that a great majority of these ipsilaterally projecting cells are $\mathrm{P} \beta$ cells. This is consistent with the soma size analysis in Figure 12 and the observations of the dendritic morphology of these cells.

\section{Physiological evidence of the nasotemporal overlap}

We recorded antidromic field potentials from the intact retina of 2 monkeys $(\mathrm{OH} 1, \mathrm{OH} 3)$ while stimulating the LGN bilaterally. Visual response fields corresponding to 2 levels of eccentricity $\left(3^{\circ}, 8^{\circ}\right)$ in the upper retina of $\mathrm{OH} 3$ (Fig. 15) appear at approximately $1^{\circ}-4^{\circ}(\mathrm{T} 1)$ and $8^{\circ}(\mathrm{T} 2)$ below the zero horizontal line. Actual recordings of field potentials from 6 locations are given in Figure $15 B$. In recordings from locations $2-5$, antidromic responses were activated by both ipsi- and contralateral stimulations. In Figure $15 \mathrm{~A}$ the locations where bilateral reponses were obtained are indicated with open circles: The horizontal width of the nasotemporal overlap was $2^{\circ}$ at $3^{\circ}$ below the fovea (see T1 in Fig. $15 \mathrm{~A}$ ), increasing to $4^{\circ}$ at $8^{\circ}$ below the fovea (see T2 in Fig. 15A).

\footnotetext{
${ }^{3}$ In fluorescent dye experiments we observed that double-labeled ganglion cells with DAPI and RITC were extremely rare $(1 / 10,000)$, suggesting that each ganglion cell gives rise to either crossed or uncrossed projection.
} 


\section{CONTRA}

A

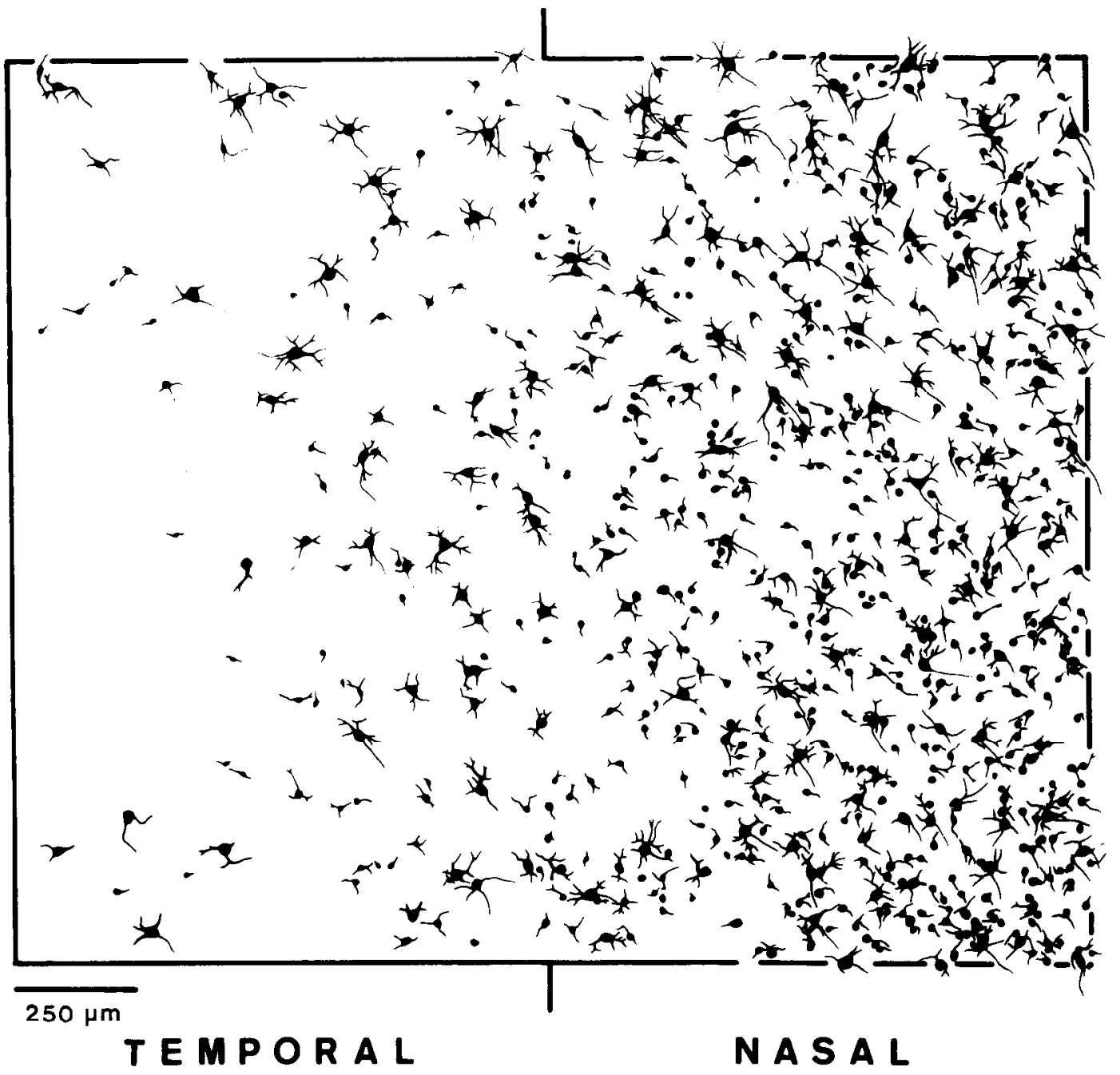

B
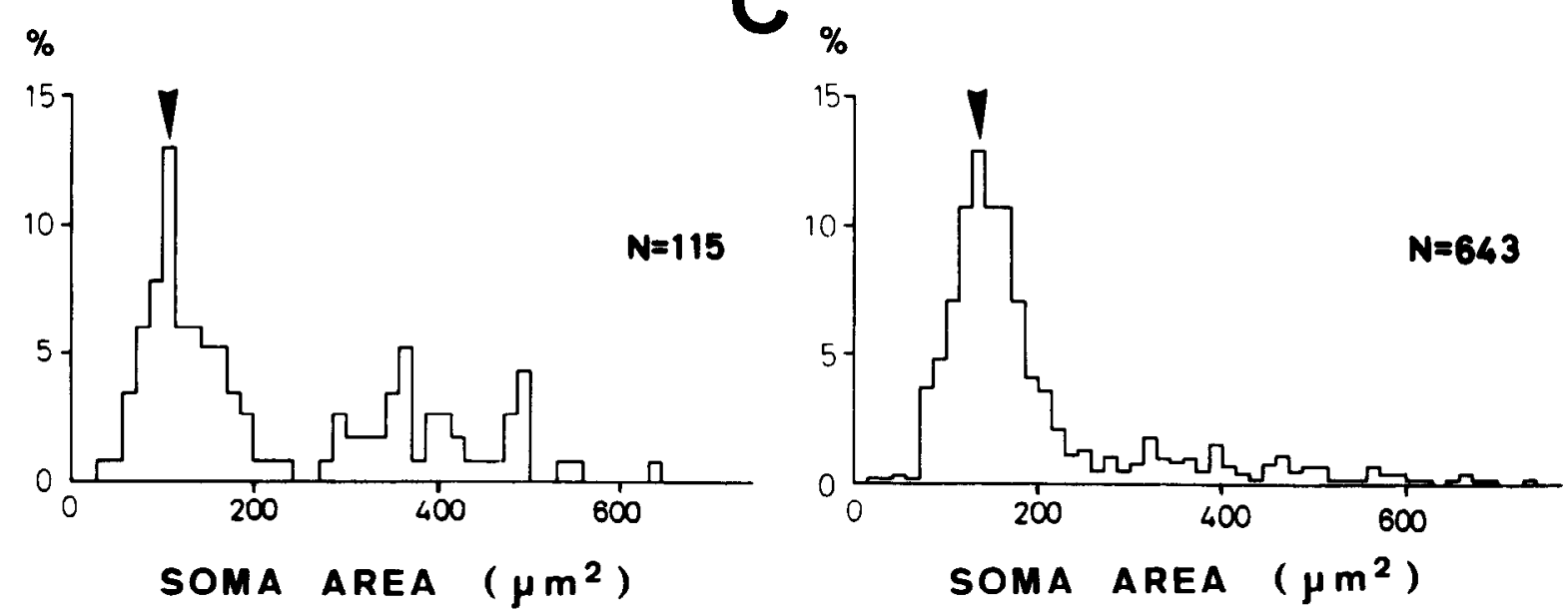

Figure 11. Soma area measurements of contralaterally projecting cells along the vertical midline $8 \mathrm{~mm}$ above the horizontal meridian in monkey AR4. $A$, Outline drawings of all labeled cells. $B$ and $C$, Soma area histograms made from the cells in the nasal $(B)$ and temporal $(C)$ halves of the square shown in $A$. Peaks at $100(B)$ and $140(C) \mu \mathrm{m}^{2}$ are indicated with arrowheads. Note that the incidence of large and small ganglion cells increases in the temporal half. 
A

IPSI

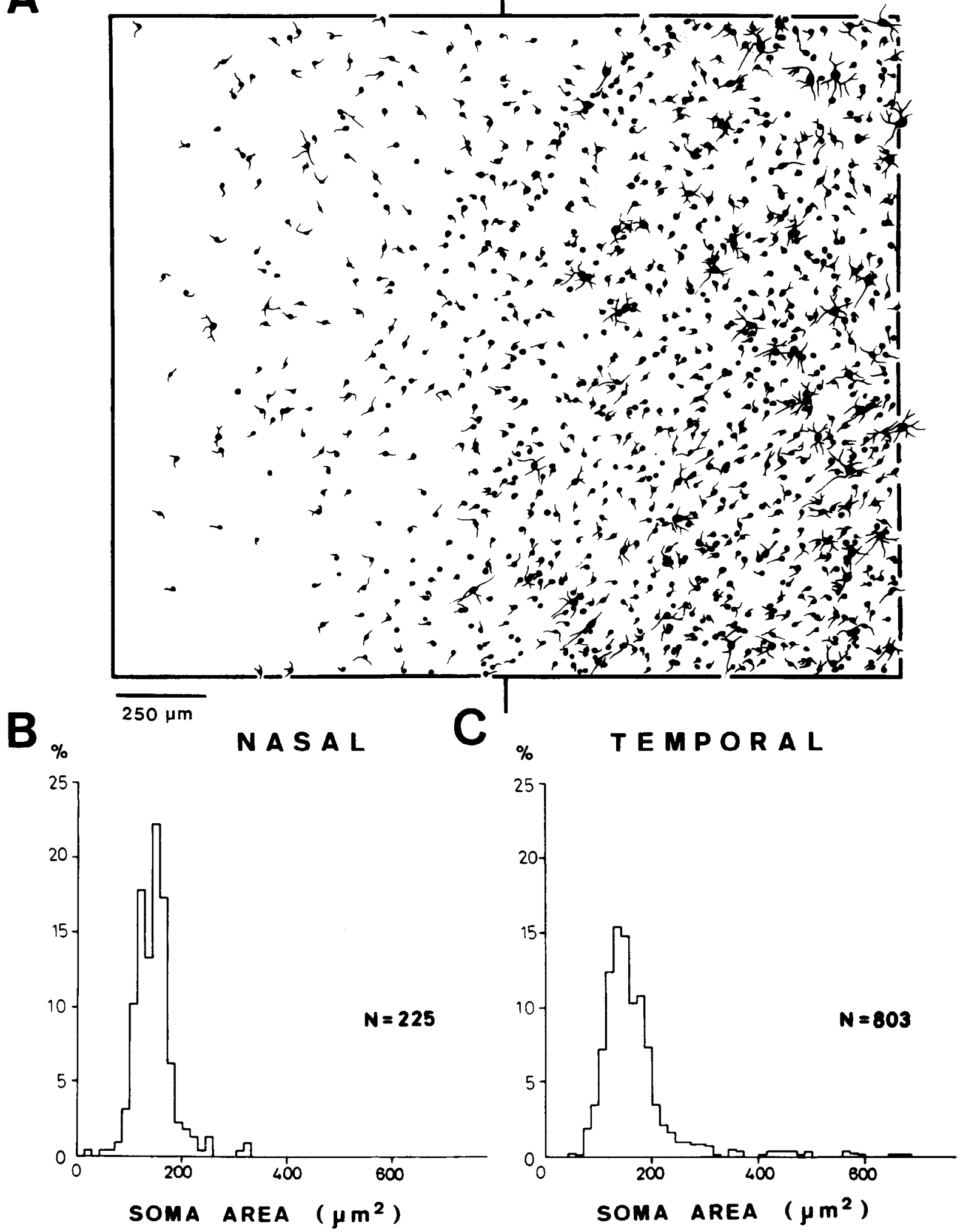

Figure 12. Soma area measurements of ipsilaterally projecting cells in monkey AR4. Conventions are the same as in Figure 11 . Note that only small to medium-sized cells remain in the nasal half. 

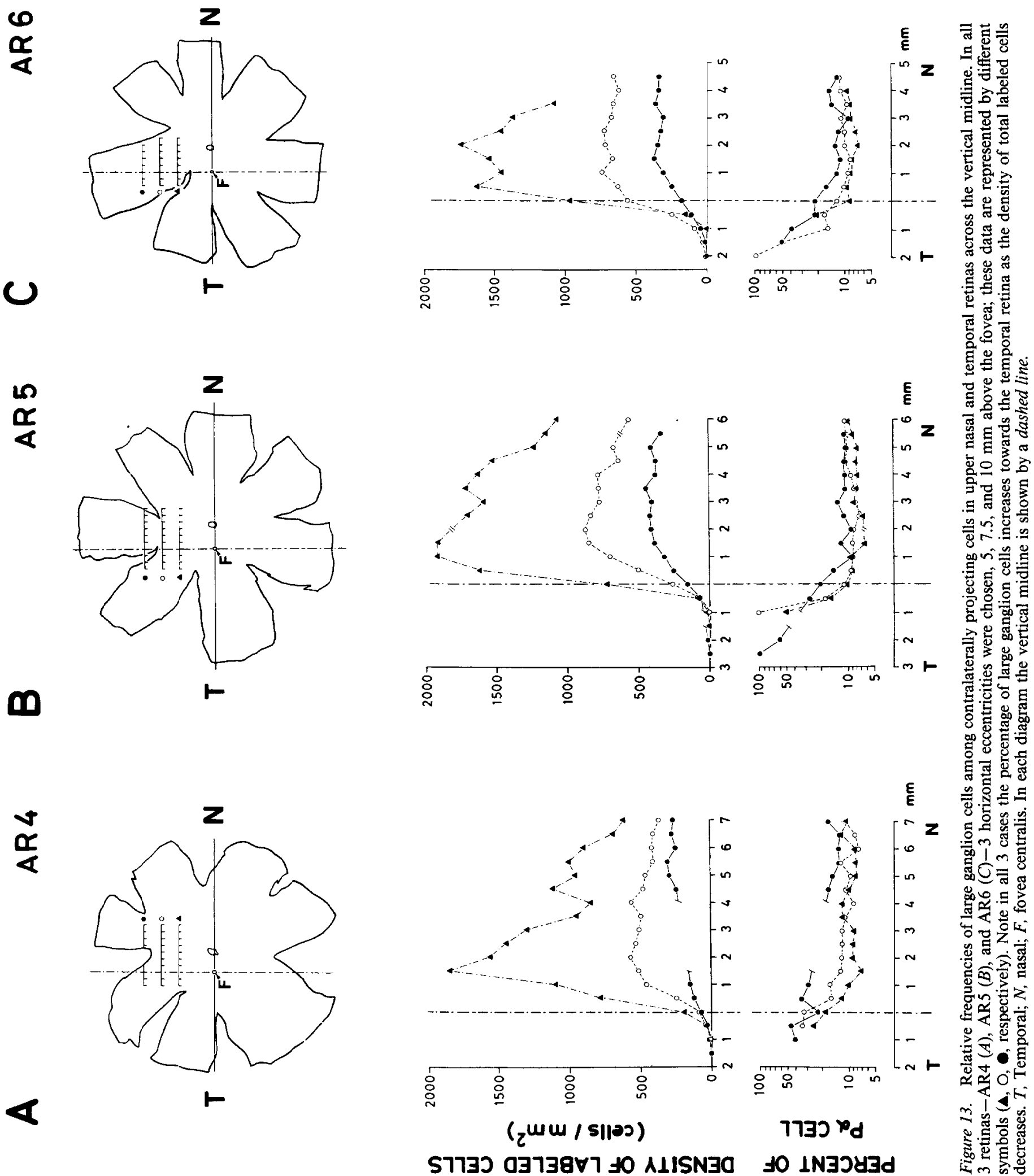

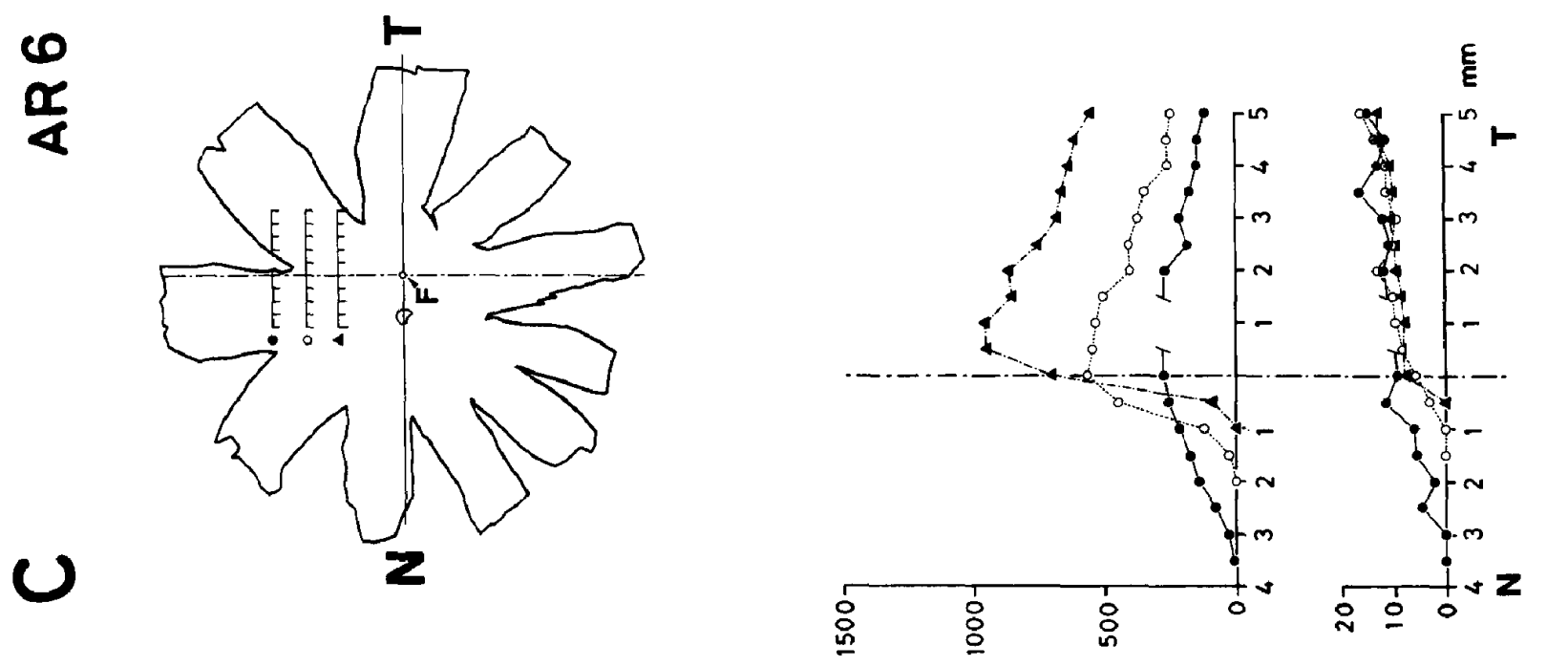

要

$\frac{1}{\alpha}$

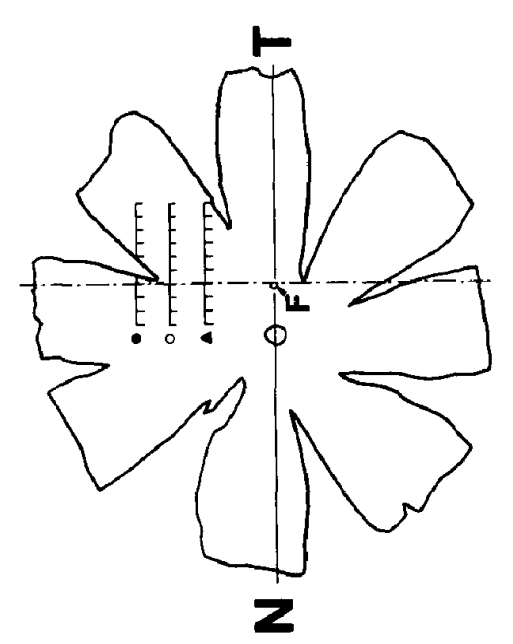

00

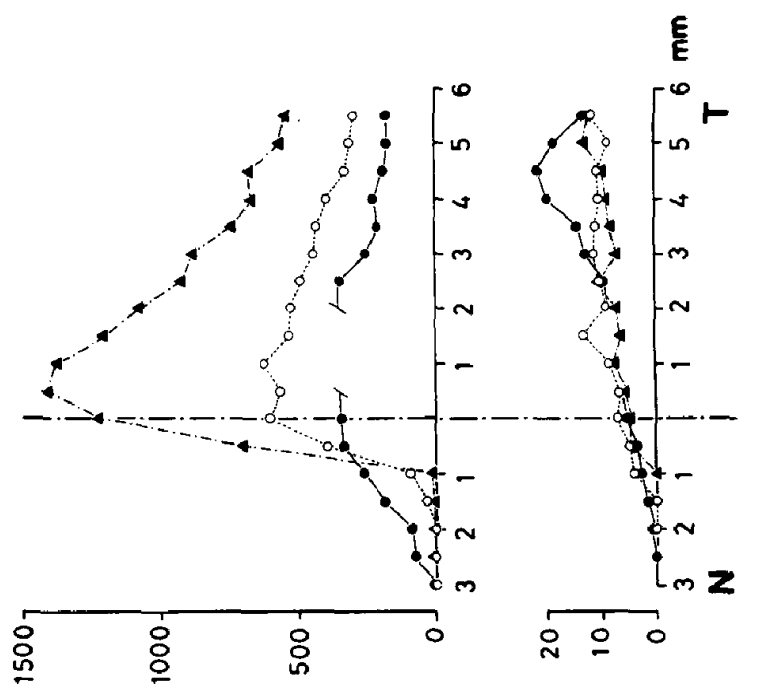

吾

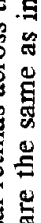

$\frac{1}{\alpha}$

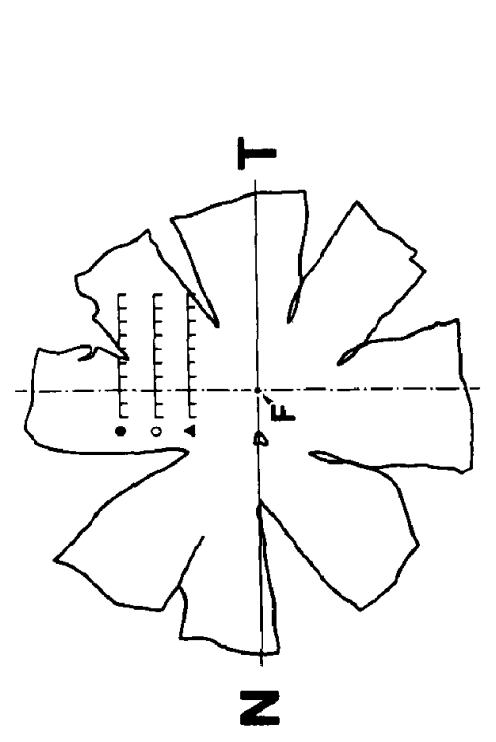

4 
$\mathrm{OH} 3$

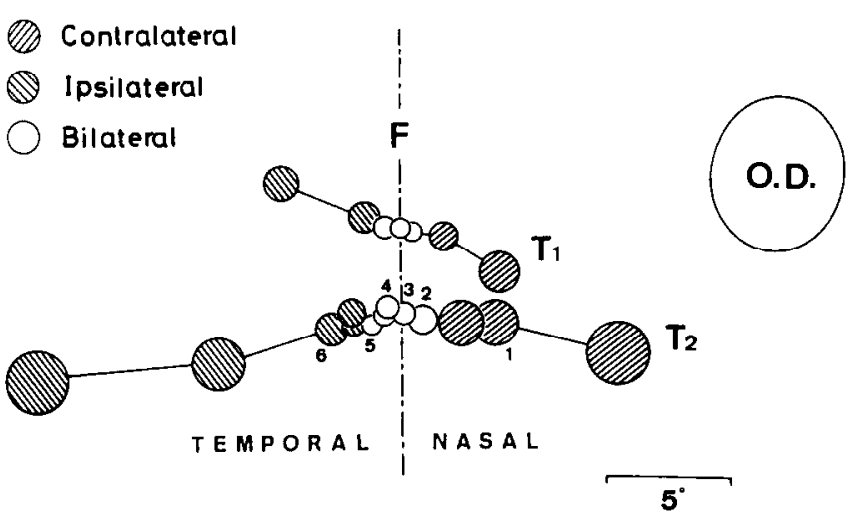

B

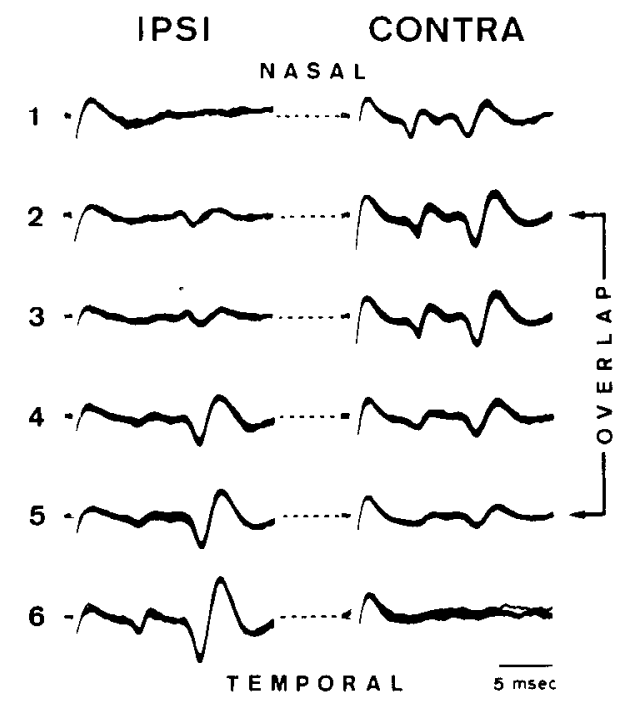

Figure 15. Physiological evidence of the nasotemporal overlap in monkey $\mathrm{OH} 3$. Antidromically activated field potentials were recorded in upper retinas nasal and temporal to the vertical midline following electrical stimulation of the LGN of each side. $A$, Locations of recordings estimated from visual response fields plotted on a tangent screen. $F$ and $O . D$., fovea centralis and optic disk, respectively. Two series of electrode penetrations were made, $T_{l}$ and $T_{2}$. Locations where bilateral responses were elicited are shown with open circles, while locations where only contra- or ipsilateral responses were obtained are shown with hatched circles. $B$ (left), Recordings of field potentials from locations 1-6 in T2 after stimulation of the ipsilateral (IPSI) LGN. B (right), Recordings of field potentials from the same locations in T2 after stimulations of contralateral (CONTRA) LGN.

After stimulation of the contralateral LGN, both fast and slow waves, termed P1 and P2 in our previous study (Fukuda et al., 1988), were activated throughout locations $1-5$ (Fig. 15B, CONTRA). After stimulation of the ipsilateral LGN, however, only the slow $\mathrm{P} 2$ wave, which presumably reflects summed activities of X-like and W-like cells (Fukuda et al., 1988), was recorded in locations 2 and 3 in the nasal portion of the overlap (Fig. $15 B$, IPSI). This coincides with the morphological observation of the retina ipsilateral to the HRP injection that medium-sized cells with small dendritic fields, presumably $\mathrm{P} \beta$ cells, are the majority in the nasal portion of the overlap.

Figure $16 \mathrm{~A}$ shows 5 tracks of recordings made along the horizontal meridian in $\mathrm{OH} 1$. The retinal locations where field po-
A $\mathrm{OH} 1$

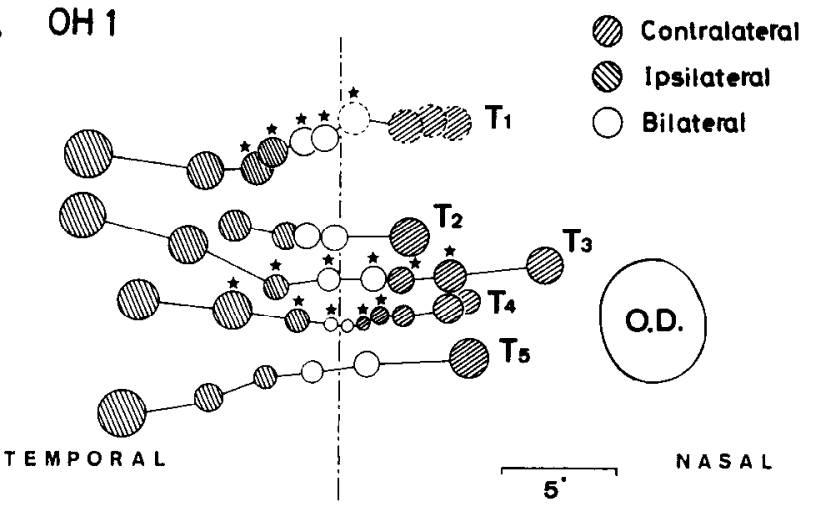

B

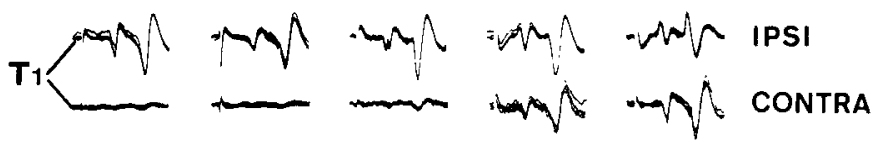

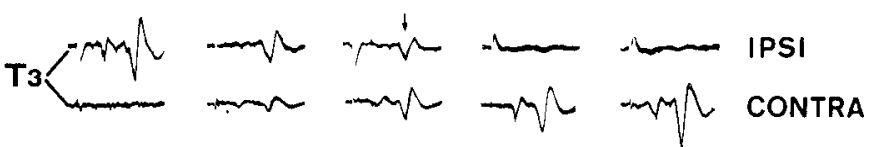

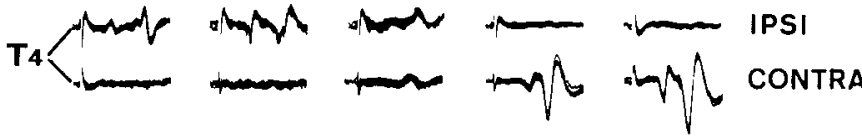

Figure 16. Physiological evidence of the nasotemporal overlap in monkey $\mathrm{OH} 1$. Antidromically activated field potentials were recorded in upper and lower retinas nasal and temporal to the vertical midline following electrical stimulation of the LGN of each side. $A$, Locations of recordings in 5 series of penetrations, $T_{l}-T_{5}$, estimated from visual response fields plotted on a tangent screen. Conventions are the same as in Figure 15. $B$, Field potentials recorded in 3 representative penetrations $\left(T_{1}, T_{3}\right.$, and $\left.T_{4}\right)$. In each case, 5 records from locations indicated with stars in the above diagram are depicted from left to right. In track $\mathrm{T} 1$, at the last 3 positions, field potentials were elicited bilaterally. In T3, bilateral responses were recorded at the second and third locations; a slow field potential (arrow) is noted at the third location in the nasal half of the overlap. In $\mathrm{T} 4$, only the third location yielded bilateral responses.

tentials were elicited from both sides of the LGN are indicated with open circles. Here again there is a clear widening of the overlap: In T4 the overlap width is about $1^{\circ}$, whereas in T1 and $\mathrm{T} 5$ the width is at least $3^{\circ}$. Figure $16 \mathrm{~B}$ shows actual recordings of the ficld potentials clicited by ipsi- and/or contralateral stimulations; field potentials were recorded from 5 locations in tracks $\mathrm{T} 1, \mathrm{~T} 3$, and $\mathrm{T} 4$ indicated by stars (from left to right) in diagram A. Again, we noted in track T3 a slow field potential in the nasal half of the overlap (indicated with an arrow) after stimulation of the ipsilateral LGN.

\section{Retrograde labeling: completeness and limitations}

The critical question in this type of morphological study is whether the ganglion cells have been throughly labeled with retrogradely transported enzyme or dye. Some smaller ganglion cells might have been insufficiently labeled, and thus histochemically undetected, because a relatively small amount of the tracers had been transported through their fine axons. We thus compared isodensity maps of HRP-labeled cells with the total 


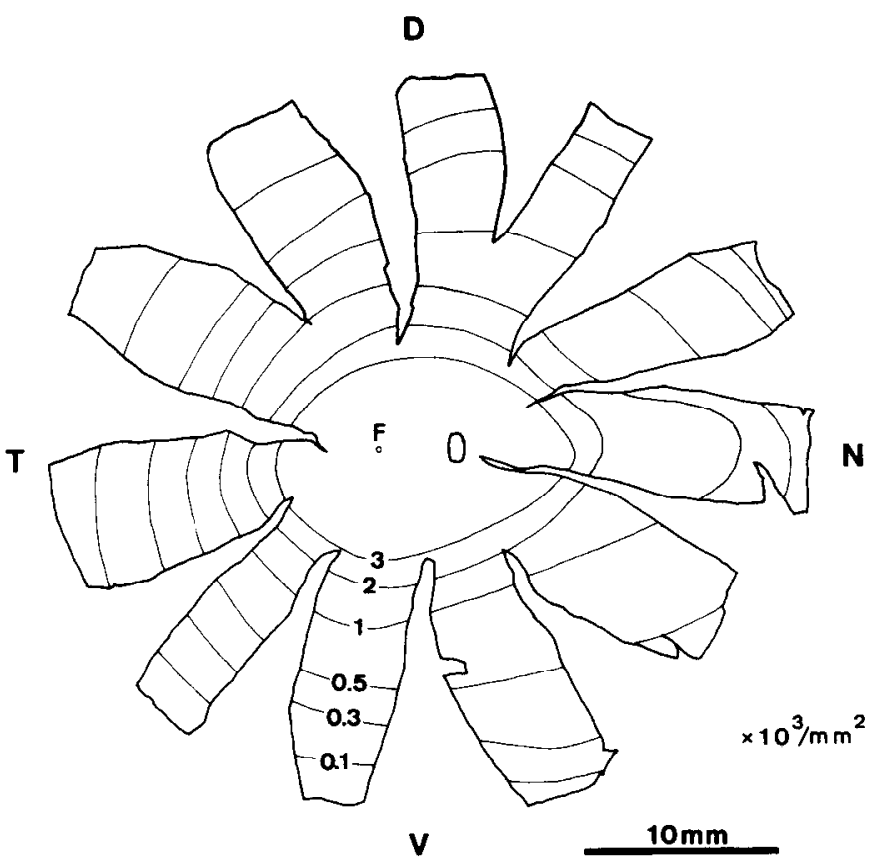

Figure 17. Isodensity map of ganglion cells in a Nissl-stained wholemount of monkey $\mathrm{OH} 1$. Note the horizontal elongation of the isodensity profiles nasal to the optic disk. $F$, Fovea centralis; $T$, temporal; $N$, nasal; $D$, dorsal; $V$, ventral.

ganglion cell density map from Nissl-stained material to verify the completeness of the labeling. We combined each pair of isodensity profiles of the retinas of AR4 and AR5 (Figs. 6, 7) by reversing the ipsilateral retina onto the contralateral one. We then compared them with the isodensity profile from the unlabeled retina of $\mathrm{OH} 1$, stained with cresyl violet (Fig. 17). The density lines in Figure 17 (for example, the $3 \times 10^{3} \mathrm{~mm}^{2}$ line) are similar to those of the combined profiles: They all showed "nasotemporal asymmetry" in ganglion cell distribution (Stone and Johnston, 1981), i.e., the relatively gradual decline of total cell density in the nasal retina compared with that in the temporal retina. Consequently, it is safe to assume that in monkeys AR4 and AR5 a great majority of the ganglion cells in both crossed and uncrossed projections were labeled by retrograde axonal transport of HRP. Although the peak cell density at 5 $\mathrm{mm}$ above the fovea in the ipsilateral retina of AR6 was slightly low compared with those of AR 4 or AR5 (see Figs. 13, 14), the estimated width of the nasotemporal overlap in the central retina of AR6 was comparable to the other 2 cases. This implies that even in monkey AR6 the majority of the cells were labeled with HRP.

Since DAPI labeled only the nucleus of ganglion cells and RITC labeled the cytoplasm, soma size analysis was not feasible in these fluorescent dye experiments. As noted in Figure 5, labeling with DAPI was always superior to that with RITC. This difference also prevented a quantitative analysis of the labeled cells in addition to quick fading of these dyes under continuous exposure to the exciting light.

\section{Discussion}

Based on retrograde labeling of ganglion cells with HRP or fluorescent dyes and on physiological recordings, we have given a more thorough description of the nasotemporal overlap and its cell composition in the monkey retina than hitherto reported. The significance of this overlap may lie in the differential distribution of its composite cell types and their projection to higher visual centers. Three lines of evidence are considered and will be discussed in successive sections: (1) width of the nasotemporal overlap, (2) nasotemporal asymmetry, and (3) cell composite of the overlap. Then, we elaborate on the possible functional roles of the 2 major $\mathrm{P} \alpha$ and $\mathrm{P} \beta$ cell systems subserving primate binocular stereopsis along the midsagittal plane.

\section{Width of the nasotemporal overlap}

The present finding that the nasotemporal overlap is narrow in the central retina $\left(0.6^{\circ}\right.$ or less) corroborates previous morphological data (Stone et al., 1973; Bunt and Minckler, 1977; Bunt et al., 1977; Leventhal et al., 1988), as well as physiological study (de Monasterio, 1978a), reporting $1^{\circ}$ of overlap in central retina of various monkeys. Our observation that the overlap is somewhat wider around the foveola $\left(1^{\circ}-1.5^{\circ}\right)$ is also consistent with other reports (Bunt et al., 1977; Leventhal et al., 1988). There is clinical evidence in patients with visual field defects from missile injury that the sparing in their fovea is $1^{\circ}-1.5^{\circ}$ wide (Koerner and Teuber, 1973).

Earlier studies in the cat (Stone, 1966; Cooper and Pettigrew, 1979; Illing and Wässle, 1981) strongly suggested that the width of the nasotemporal overlap in the monkey retina may also increase with eccentricity. Indeed, this was true of the overlap in the monkey: The overlap width was approximately $15^{\circ}$ in the upper periphery and $5^{\circ}-9^{\circ}$ in the lower periphery. Our physiological study confirms this widening. A similar increase in the amount of the overlap has been reported in another macaque and in the squirrel monkeys as well (Leventhal et al., 1988). There is further evidence from single- and multiunit recording in the LGN of the rhesus monkey, for which it was reported that, particularly in the upper and lower periphery, receptive fields are noted in the ipsilateral hemifield (Malpeli and Baker, 1975).

The fact that the overlap, narrow in the central retina, widens with eccentricity accounts for the observation in perimetric studies of the visual field in patients with unilateral occipital lobectomy. Huber (1970) has reported that in some occasions the separation line between the intact and blinded hemifields moves away from the vertical meridian to form an overshoot field in the periphery, but that in the central field it clings to the neighborhood of the fixation point. This is exactly what can be expected from the nasotemporal overlap pattern established here in the monkey.

\section{Nasotemporal asymmetry}

Within the nasotemporal overlap. We have noted that the distribution of ipsilaterally projecting ganglion cells extended more into the nasal hemiretina than that of the contralaterally projecting cells into the temporal hemiretina. This asymmetry was particularly apparent in the perifoveal retina. That the overlap. is mainly due to this asymmetric distribution of crossed and uncrossed projections was demonstrated more directly in our fluorescent dye experiments. Leventhal et al. (1988) reached essentially the same conclusion in retinas of both macaque and squirrel monkeys. Earlier reports by Bunt et al. (Bunt and Minckler, 1977; Bunt et al., 1977), however, appear to be at variance with this result, which could result from methodological differences or interspecies variations.

The perifoveal asymmetry in the distribution of crossed and 
uncrossed projecting cells, if true in humans as well, may account for the controversial clinical obscrvations of macular or foveal "sparing" and "splitting." That is, besides possible factors such as individual differences or the difficulty of fixation in patients with hemispheric injury (Spalding, 1952; Koerner and Teuber, 1973; Harrington, 1981), foveal sparing or splitting may be observed depending on whether the eye tested is ipsi- or contralateral to the lesioned hemisphere.

Outside of the overlap. We also noted asymmetric distributions of HRP-labeled cells in the nasal and temporal hemiretina outside of the overlap: Compared with those of the ipsilateral ones, high-density areas of contralaterally projecting cells are elongated along the horizontal meridian into the nasal periphery. This confirms earlier reports based on ganglion cell density maps of Nissl-stained (Stone and Johnston, 1981; Perry and Cowey, 1985) and HRP-labeled retinas (Perry et al., 1984). The significance of this asymmetry becomes obvious in view of the recent finding by LeVay et al. (1985) that ocular dominance stripes of the striate cortex innervated by crossed retinal projections from nasal retina beyond the optic disk are wider than those innervated by uncrossed projections from the corresponding part of temporal retina. Furthermore, this asymmetric distribution accounts for unequal retinal representation between the contra- and ipsilaterally innervated laminas of the LGN as well (Connolly and Van Essen, 1984).

\section{Cell composite of the nasotemporal overlap: comparison with other species}

We have demonstrated that large ganglion cells, presumably $\mathrm{P} \alpha$ cells, in the temporal portion of the overlap project contralaterally, whereas medium-sized cells, most of which are $\mathrm{P} \beta$ cells, in the nasal portion of the overlap project ipsilaterally. This appears to be characteristic of the nasotemporal overlap of the monkey retina. In the cat retina, a great majority of $\alpha$ cells ( $Y$ cells) in the temporal portion of the overlap also project contralaterally, but as the nasotemporal division is quite sharp in the nasal retina, only a few $\beta$ cells ( $\mathrm{X}$ cells) project ipsilaterally from the narrow strip of the overlap (Stone and Fukuda, 1974; Kirk et al., 1976b; Cooper and Pettigrew, 1979; Illing and Wässle, 1981). We have also shown that small ganglion cells in the temporal portion of the overlap project contralaterally in the Japanese monkey. These cells appear to be $\mathrm{P} \gamma$ cells in dendritic morphology. A recent report by Leventhal et al. (1988) on another macaque and the squirrel monkeys is in basic agreement with our findings. In the cat, it has been verified that the small cells that project contralaterally from the temporal retina are W or sluggish cells (Stone and Fukuda, 1974; Kirk et al., 1976a).

The nasotemporal division of the rabbit retina differs from either of the above species. In the rabbit, the overlap of the crossed projections extends far into the temporal retina so that both crossed and uncrossed projecting cells intermingle in the temporal retina (Provis and Watson, 1981). Similar nasotemporal divisons have also been reported in other rodents (Hsiao and Fukuda, 1984; Dreher et al., 1985; Wakakuwa et al., 1985; Reese and Cowey, 1986). Interestingly, it appears to be a common trait in these animals with lateralized eyes to have a concentration of both crossed and uncrossed projecting large ganglion cells in the temporal retina. Thus, it is likely that these large ganglion cells play a major role in their binocular vision, as described in detail in our recent work on the chipmunk retinogeniculate projection (Morigiwa et al., 1988).

\section{Possible mechanisms for binocular stereopsis along the midsagittal plane}

It is important to note that a clear nasotemporal overlap was obtained not only by HRP injections into the optic tract, but also by fluorescent dye injections into the LGN. This implies that ganglion cell axons that arise from the overlap region of the retina terminate in the LGN. Indeed, several physiological studies in both squirrel and rhesus monkeys report that in recordings from the LGN and striate cortex, receptive fields invading into the opposite hemifield across the zero vertical meridian were observed (Cowey, 1964; Malpeli and Baker, 1975). On the other hand, after unilateral injections of HRP into the superior colliculus of the rhesus monkey, Cowey and Perry (1980) found no labeled cells in the opposite hemiretina, which eliminates the possibility of retinotectal projection from the nasotemporal overlap.

Based on the asymmetric distributions and differential retinogeniculate projections of $\mathrm{P} \alpha$ and $\mathrm{P} \beta$ cells from the nasotemporal overlap, we propose a hypothesis on their functional roles in primate binocular stereopsis along the midsagittal plane. As shown in Figure 18, an object placed within the filled diamond area in front of the fixation point falls within the visual field served by the temporal portion of the overlap of both eyes. Since the crossed projection from the temporal overlap region consists mainly of $\mathrm{P} \alpha$ cells, the image of the near object is transmitted by $\mathrm{P} \alpha$ cells in each retina to the magnocellular cells of the LGN (Dreher et al., 1976; Schiller and Malpeli, 1978; Kaplan and Shapley, 1982; but see Shapley and Perry, 1986). The information from the magnocellular cells converges onto single cells in the striate cortex, enabling binocular single vision of the near object. $\mathrm{P} \beta$ cells, on the other hand, appear to be suited for binocular single vision of an object placed in the striped diamond area beyond the fixation point. Since uncrossed projections from the nasal portion of the overlap arise mainly from $\mathrm{P} \beta$ cells, the image of the far object is transmitted by $\mathrm{P} \beta$ cells to the parvocellular cells of the LGN and onto single cortical cells. We thus conclude that the $\mathrm{P} \alpha$ cell system is suited for binocular single vision of near objects, while the $\mathrm{P} \beta$ cell system is suited for that of far objects, which together contribute to the primate binocular stercopsis of the midsagittal planc.

Our hypothesis is in agreement with Levick's (1977) suggestion concerning the cat retina that one of the $\alpha$ cell functions (Y or brisk transient cells) is the detection of near objects on the midsagittal plane. The hypothesis is also consistent with the response properties of $\mathrm{Y}$-like cells (physiological correlates to $\mathrm{P} \alpha$ cells) and $\mathrm{X}$-like cells (physiological correlates to $\mathrm{P} \beta$ cells) in the retina and LGN of the monkey (Dreher et al., 1976; de Monasterio, 1978a, b; Schiller and Malpeli, 1978; Kaplan and Shapley, 1982). Near objects have a larger retinal image than far objects; when moved in the frontoparallel plane, near objects undergo greater displacement in degree per unit time than far objects. In accordance, Y-like cells in the monkey have larger receptive field center sizes and respond to faster moving stimuli than X-like cells.

The present study has demonstrated that the monkey retina has a characteristic overlap region along the vertical mcridian: Not only does the proportion of contralaterally projecting $\mathrm{P} \alpha$ cells increase in the temporal portion of the overlap, but the ipsilaterally projecting $\mathbf{P} \beta$ cells extend further into the nasal portion of the overlap region. This overlap system has enabled binocular depth discrimination of objects lying farther from and 


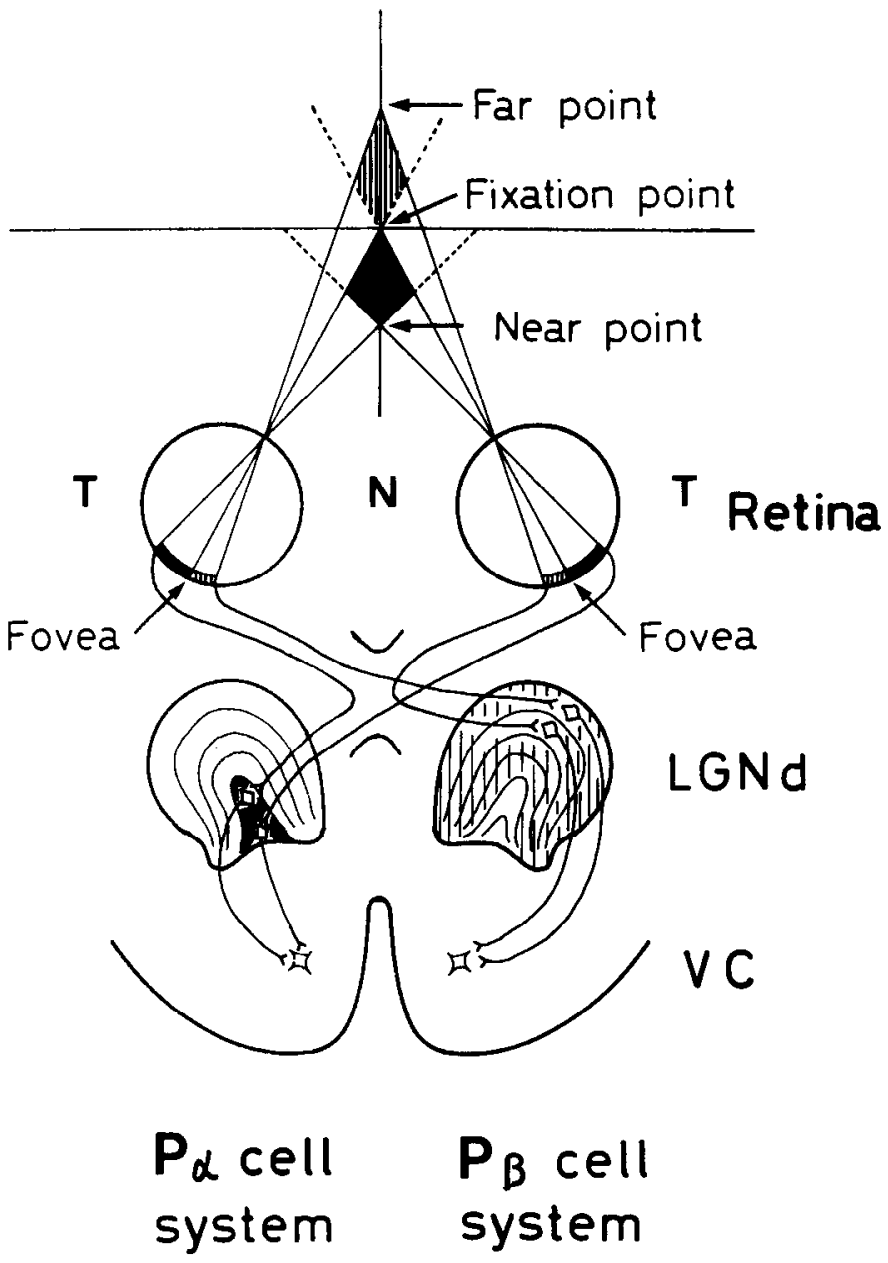

Figure 18. Hypothetical diagram illustrating a possible functional segregation of $\mathrm{P} \alpha$ and $\mathrm{P} \beta$ cell systems underlying binocular stereopsis along the midsagittal plane. An object in front of the fixation point along the midsagittal plane (filled area) falls within the visual field of the temporal portions of the nasotemporal overlap where crossed projections arise from $\mathrm{P} \alpha$ cells. The information from $\mathrm{P} \alpha$ cells is transmitted onto a single cell in the primary visual cortex via magnocellular cells in the LGN. On the other hand, an object beyond the fixation point (striped area) falls within the visual field of the nasal portion of the overlap where uncrossed projections arise from $\mathbf{P} \beta$ cells. Their information is transmitted via parvocellular cells in the LGN onto a single cell in the visual cortex.

nearer to the fixation point and has increased stereoacuity of distant objects in the midsagittal plane. This appears to be unique to the monkey, endowing it with a particularly wcll developed system for binocular single vision.

\section{References}

Adams, J. (1981) Heavy metal intensification of DAB-based HRP reaction product. J. Histochem. Cytochem. 29: 775.

Bartlett, J. R., R. W. Doty, and J. Pecci-Saavedra (1973) Mesencephalic control of lateral geniculate nucleus in primates. III. Modifications with state of alertness. Exp. Brain Res. 18: 214-224.

Bishop, P. O. (1981) Binocular vision. In Adler's Physiology of the Eye: Clinical Application, R. A. Moses, ed., pp. 575-649, Mosby, St. Louis.

Blakemore, C. (1969) Binocular depth discrimination and the nasotemporal division. J. Physiol. (Lond.) 205: 471-497.

Bunt, A. E., and D. S. Minckler (1977) Foveal sparing. Arch. Ophthalmol. 95: 1445-1447.

Bunt, A. E., D. S. Minckler, and G. W. Johanson (1977) Demon- stration of bilateral projection of central retina of the monkey with horseradish peroxidase neuronography. J. Comp. Neurol. 71:619630.

Connolly, M., and D. C. Van Essen (1984) The representation of the visual field in the parvocellular and magnocellular layers of the lateral geniculate nucleus in the macaque monkey. J. Comp. Neurol. 226: 544-564.

Cooper, M. L., and J. D. Pettigrew (1979) The decussation of the retinothalamic pathway in the cat, with a note on the major meridian of the cat's eye. J. Comp. Neurol. 187: 285-312.

Cowey, A. (1964) Projection of the retina on to striate and peristriate cortex in the squirrel monkey, Saimiri sciureusii. J. Neurophysiol. 27: 366-393.

Cowey, A., and Perry, V. H. (1980) The projection of the fovea to the superior colliculus in rhesus monkey. Neuroscience 5: 53-61.

de Monasterio, F. M. (1978a) Properties of concentrically organized $\mathrm{X}$ and $\mathrm{Y}$ ganglion cells of the macaque retina. J. Neurophysiol. 41: $1394-1417$

de Monasterio, F. M. (1978b) Center and surround mechanisms of opponent-color $\mathrm{X}$ and $\mathrm{Y}$ ganglion cells of retina of macaques. $\mathrm{J}$. Neurophysiol. 41: 1418-1434.

Dreher, B., Y. Fukada, and R. W. Rodieck (1976) Identification, classification and anatomical segregation of cells with X-like and Y-like properties in the lateral geniculate nucleus of old-world primates. J. Physiol. (Lond.) 258: 433-452.

Dreher, B., A. J. Sefton, S. Y. K. Ni, and G. Nisbett (1985) The morphology, number, distribution and central projections of class I retinal ganglion cells in albino and hooded rats. Brain Behav. Evol. 26: $10-48$.

Fukuda, Y., H. Sawai, K. Wakakuwa, and M. Watanabe (1986) Nasotemporal division of the monkey retina. Soc. Neurosci. Abstr. 12: 636.

Fukuda, Y., M. Watanabe, K. Wakakuwa, H. Sawai, and K. Morigiwa (1988) Intraretinal axons of ganglion cells in the Japanese monkey (Macaca fuscata): Conduction velocity and diameter distribution. Neurosci. Res. 6: 53-71.

Graham, R. J., Jr., and M. J. Karnovsky (1977) The early stages of absorption of injected horse-radish peroxidase in the proximal tubules of mouse kidney: Ultrastructural cytochemistry by a new technique. J. Histochem. Cytochem. 14: 291-302.

Hanker, I. S., P. E. Yates, C. B. Metz, and A. Rustioni (1977) A new specific, sensitive, non-carcinogenic reagent for the demonstration of horseradish peroxidase. Histochem. J. 9: 789-792.

Harrington, D. O. (1981) The Visual Fields, 5th ed., pp. 335-349, Mosby, St. Louis.

Hsiao, C.-F., and Y. Fukuda (1984) Plastic changes in the distribution and soma size of retinal ganglion cells after neonatal monocular enucleation in rats. Brain Res. 301: 1-12.

Huber, A. (1970) Homonymous hemianopsia after removal of one occipital lobe. Excerpta Medica 222: 1333-1338.

Illing, R.-B., and H. Wässle (1981) Retinal projection to the thalamus in the cat: A quantitative investigation and a comparison with the retinotectal pathway. J. Comp. Neurol. 202: 265-285.

Kaplan, E., and R. M. Shapley (1982) X and Y cells in the lateral geniculate nucleus of macaque monkeys. J. Physiol. (Lond.) 330:125143.

Kirk, D., W. R. Levick, and B. Cleland (1976a) The crossed or uncrossed destination of axons of sluggish-concentric and non-concentric cat retinal ganglion cells. Vision Res. 16: 233-236.

Kirk, D., W. R. Levick, B. Cleland, and H. Wässle (1976b) Crossed and uncrossed representation of the visual ficld by brisk-sustained and brisk-transient cat retinal ganglion cells. Vision Res. 16: 225231.

Koerner, F., and H.-L. Teuber (1973) Visual field defects after missile injuries to the geniculo-striate pathway in man. Exp. Brain Res. 18 88-113.

Kuypers, H. G. J. M., C. E. Gatsman-Berreovoets, and R. E. Padt (1977) Retrograde axonal transport of fluorescent substances in the rat's forebrain. Neurosci. Lett. 6: 127-135.

LeVay, S., M. Connolly, J. Honde, and D. C. Van Essen (1985) The complete pattern of ocular dominance stripes in the striate cortex and visual field of the macaque monkey. J. Neurosci. $5: 486-490$.

Leventhal, A. G., W. R. Rodieck, and B. Dreher (1981) Retinal ganglion cell classes in the Old World monkey: Morphology and central projections. Science 213: 1139-1142. 
Leventhal, A. G., J. A. Steven, and D. J. Vitek (1988) The nasotemporal division in primate retina: The neural bases of macular sparing and splitting. Science 240: 66-67.

Levick, W. R. (1977) Participation of brisk transient retinal ganglion cells in binocular vision-a hypothesis. Proc. Aust. Physiol. Pharmacol. Soc. 8: 9-16.

Malpeli, J. G., and F. H. Baker (1975) The representation of the visual field in the lateral geniculate nucleus of Macaca mulatta. J. Comp. Neurol. 161: 569-594.

Morigiwa, K., H. Sawai, K. Wakakuwa, Y. Mitani-Yamanishi, and Y. Fukuda (1988) Retinal inputs and laminar distributions of the dorsal lateral geniculate relay cells in the eastern chipmunk (Tamias sibiricus asiaticus). Exp. Brain Res. 71: 527-540.

Peichl, L., H. Ott, and B. B. Boycott (1987) Alpha ganglion cells in mammalian retinae. Proc. R. Soc. London 231: 169-197.

Perry, V. H., and A. Cowey (1984) Retinal ganglion cells that project to the superior colliculus and pretectum in the macaque monkey. Neuroscience 12: 1125-1137.

Perry, V. H., and Cowey A. (1985) The ganglion cell and cone contribution in the monkey's retina: Implications for central magnification factors. Vision Res. 25: 1795-1810.

Perry, V. H., R. Oehler, and A. Cowey (1984) Retinal ganglion cells that project to the dorsal lateral geniculate nucleus in the macaque monkey. Neuroscience 12:1101-1123.

Provis, J. M., and C. R. R. Watson (1981) The distribution of ipsilaterally and contralaterally projecting ganglion cells in the retina of the pigmented rabbit. Exp. Brain Res. 44: 82-92.

Reese, B. E., and A. Cowey (1986) Large retinal ganglion cell in the rat: Their distribution and laterality of projection. Exp. Brain Res. 61: $375-385$.

Rodieck, R. W., K. F. Binmoeller, and J. Dineen (1985) Parasol and midget ganglion cells of the human retina. J. Comp. Neurol. 233. $115-132$.

Rodieck, R. W., D. M. Dacey, and M. Watanabe (1987) Some other ganglion cell types of the primate retina. Invest. Ophthalmol. Vis. Sci. (Suppl.) 28: 261.
Rolls, E. T., and A. Cowey (1970) Topography of the retina and striate cortex and its relationship to visual acuity in rhesus monkeys and squirrel monkeys. Exp. Brain Res. 10: 298-310.

Sarthy, P. V., and G. W. Balkema (1981) Retrograde labeling and dissociation of mouse retinal ganglion cells. Neurosci. Lett. 25: 205208.

Schiller, P. H., and J. G. Malpeli (1978) Functional specificity of lateral geniculate nucleus laminae of the thesus monkey. J. Neurophysiol. 41: 788-797.

Shapley, R. M., and V. H. Perry (1986) Cat and monkey retinal ganglion cells and their visual functional roles. TINS 9: 229-235.

Spalding, J. M. K. (1952) Wounds of the visual pathway, Part II. The striate cortex. J. Neurol. Neurosurg. Psychiatry 15: 169-183.

Stone, J. (1966) The nasotemporal division of the cat's retina. J. Comp. Neurol. 136: 585-600.

Stone, J., and Y. Fukuda (1974) The nasotemporal division of the cat's retina re-examined in terms of $\mathrm{Y}-, \mathrm{X}$ - and $\mathrm{W}$-cells. J. Comp. Neurol. 155: 377-394.

Stone, J., and E. Johnston (1981) The topography of primate retina: A study of the human, bushbaby and New- and Old-World monkey. J. Comp. Neurol. 196: 205-223.

Stone, J., J. Leiceter, and S. M. Sherman (1973) The nasotemporal division of the monkey's retina. J. Comp. Neurol. 150: 333-348.

Suyama, H. (1986) Morphological types of ganglion cells of the monkey retina. J. Jpn. Ophthalmol. Soc. 90: 145-151 [in Japanese with English abstract].

Thanos, S., M. Vidal-Sanz, and A. J. Aguayo (1987) The use of rhodamine B-isothiocyanate (RITC) as an anterograde and retrograde tracer in the adult rat visual system. Brain Res. 406: 317-321.

Wakakuwa, K., A. Washida, and Y. Fukuda (1985) Ipsilaterally projecting retinal ganglion cells in the eastern chipmunk (Tamias sibiricus asiaticus). Neurosci. Lett. 55: 219-224.

Watanabe, M., R. W. Rodieck, and D. M. Dacey (1987) Parasol ganglion cells of macaque and baboon retinas. Invest. Ophthalmol. Vis. Sci. (Suppl.) 28: 261. 